\title{
اختبار مؤشرات الصدق والثبات لمصفوفات ريفن المتتابعة المتقدم \\ في مدينة مصراتة
}

\section{سلوى عبدالحميد الضلعة}

الأكاديمية الليبية - فرع مصراتة
خالد محمد المدلي 1

كلية الآداب - جامعة مصراتة

تاريخ التقديم: 07-10-2019 ، تاريخ القبول: 17-11- 2019، نشر إلكترونيا في 23-11-2019

https://doi.org/10.36602/faj.2019.n14.08

ملخص البحث:

يهدف هذا البحث إلى اختبار صلاحية المصفوفات المتتابعة المتقدم للاستخدام في مدينة مصراتة من خلال تحليل فقراته وحساب الخصائص السيكومترية للاختبار، وشنملت عينة البحث على 400 تلميذ وتلميذة (171 ذكور، 229 إناث) من مدراس مدينة مصراتة، تتراوح أعمار العينة بين 12: 17 سنة، بمتوسط يساوي 14.31 (انخراف معياري 1.71)، وأظهرت النتائج معدلات صعوبة لفقرات الاختبار - المجموعة الثانية تتراواح من لئن 10\% إلى 100\% (م = 168.56\%) ومعاملات تمييز عن طريق الارتباط الثنائي تتراوح من 02. إلى 56. (م =22.)، كما أظهر الاختبار مؤشرات جيدة على صدقه من خلال قدرته على تحقيق تمايز المجموعات العمرية في معدلات الذكاء، وقدرته على التمبيز بين ذوي الدرجات العالية وذوي الدرجات الدنيا من الذكاء، وبين المتفوقين وغير المتفوقين، وارتباطه القوي بدرجات التحصيل الدراسي، كما أظهر المقياس مؤشرات قوية للثبات من خلال الاستقرار عبر الزمن (89.)، واتساقه الداخلي (الفا = 70.)، وتمت مناقشة النتائج في ضوء الأدبيات ذات العلاقة. الكلمات المفتاحية: الصدق، الثبات، مصغوفات رينن المتتابعة المتقدم، الخصائص السيكومترية.

Khalidelmadani@misuratau.edu.ly ${ }^{1}$ 


\title{
The Examination of Validity and Reliability Indicators of The Raven's Advanced Progressive Matrices on Misurata City
}

Khalid M. Elmadani

Misurata University
Salwa A. Aldolha

Libyan Acadimy- Misurata

\begin{abstract}
This paper reports the psychometric properties of the Raven's Advanced Progressive Matrices (APM) among a Libyan student sample from Misurata. The study sample consisted 400 participants (171 males, 229 females), their age ranged from 12 to 17 years $(\mathrm{M}=$ $14.31, \mathrm{SD}=1.17)$. The results showed that item difficulty indices on set II ranged from $10 \%$ to $100 \%(M=68.56 \%)$ and all of them needed to be rearranged according to their difficulty index, and that discrimination indices ranged from .02 to $.56(\mathrm{M}=.22)$. The construct and Criterion validity of APM were confirmed; Moreover, test -retest reliability and Cronbach's alpha reliability values of the APM test were strong. The results were discussed in the light of the related literature.
\end{abstract}

Kayword: Raven's Advanced Progressive Matrices, reliability, validity, psychometric properties

1

تعد اختبارات القدرة على التفكير المنطقي - أو كما يسميها كاتل الذكاء السائل

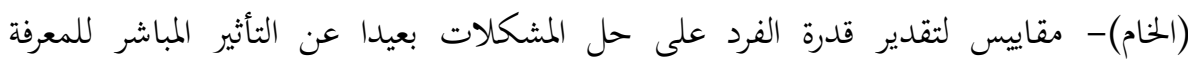

المستمدة من الخبرات السابقة، وهي ليست فقط اختبارات لقياس مثل هذا النوع من العمليات

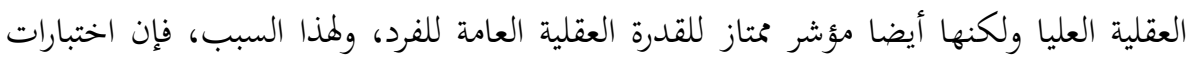

الذكاء الخام شاع استخدامها في التطبيقات والبحوث النفسية، وبشكل خاص اختبارات الذكاء

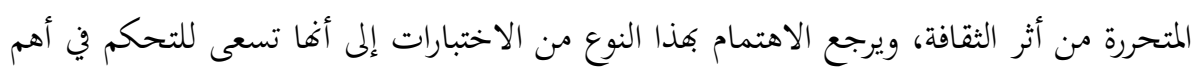

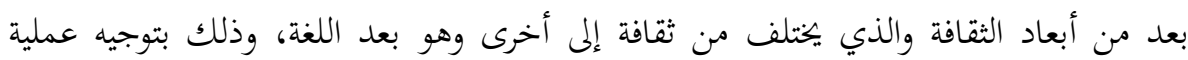

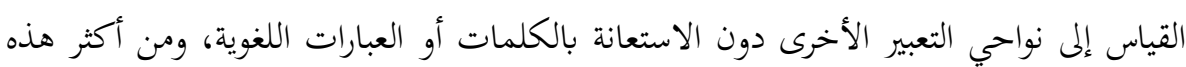


الاختبارات شيوعا مصفوفات ريفن المتتابعة والتي تعتبر بنظر الباحثين في علم النفس من أفضل الأدوات المتوفرة حتى الآن لقياس العامل العام إن لم يكن أفضلها على الإطلاق (تخائيل، 2006

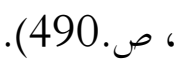

ونظرا لأهمية قياس القدرات العقلية في الميدان التعليمي لإعداد البرامج التعليمية الهادفة،

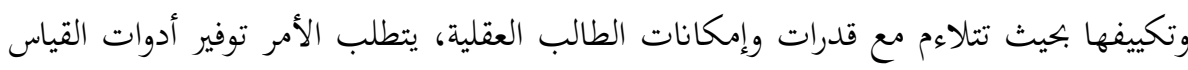

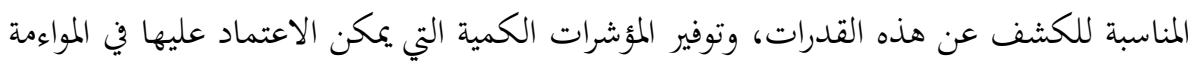
بين برامج التعليم والتدريب وقدرات الفرد، وتُعين أصحاب القرارات في توجيه تنمية الإنسان نهو التكامل (المدني، 2017، ص. 143)، وفي مجتمعنا اللبيي، ومن خلال خبرة الباحثين في المجال التربوي، يعاني العاملون في الميدان التعليمي من ندرة اختبارات القدرات العقلية الموثوقة التي تعينهم

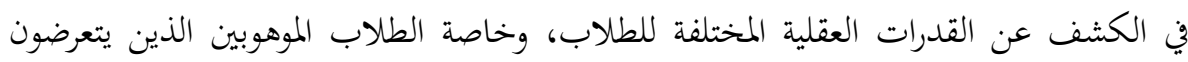

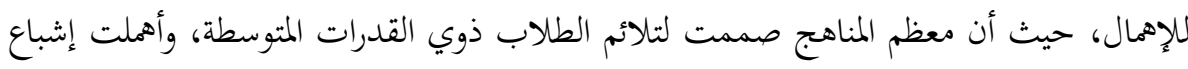
حاجات الطلاب الموهوبين، وتنمية إبداعهم وتفوقهم، لهذا، يأتي هذا البحث مساهمة في توفير

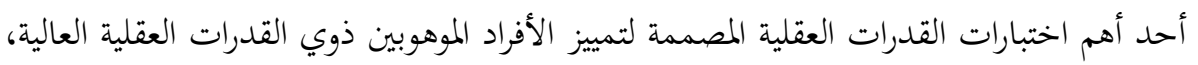
من خلال العمل على إعداد اختبار مصفوفات ريفن المتتابعة المتقدم للاستخدام في مدينة مصراتة، وتحليل فقراته، واختبار صلاحيته محلياً.

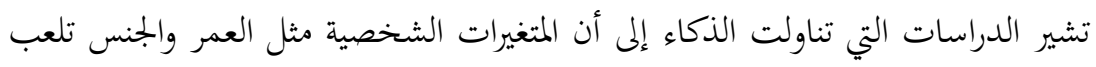

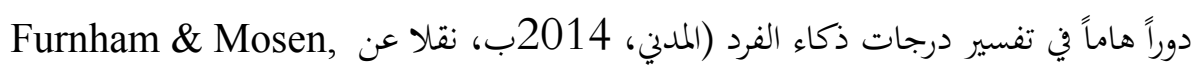
2009)، فبينما اتفقت دراسات استخدمت مصفوفات ريفن المتتابعة، على وجود علاقة طردية

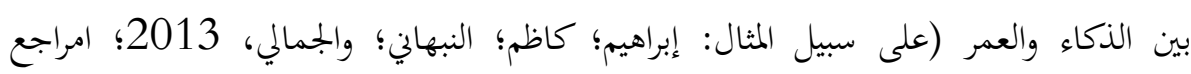

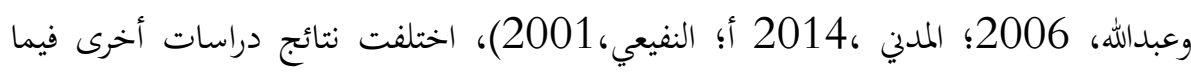
يتعلق بالفروق بين الذكور والإناث. في هدا المجال، ربط بعض الباحثين الفروق بين الجنسين في درجة الذكاء بمرحلة النمو،

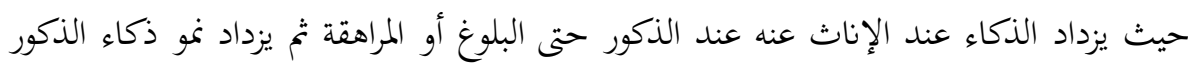

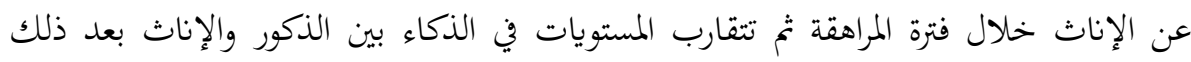

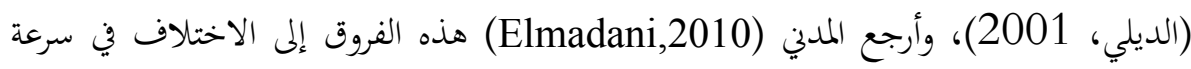


النمو بين الجنسين، حيث تنمو الإناث أسرع من الذكور حتى فترة البلوغ أو المراهقة، تم يحدث العكس في فترة المراهقة.

من جهة أخرى لم بحد عدد من الدراسات المحلية فروقا دالة بين الذكور والإناث عندما

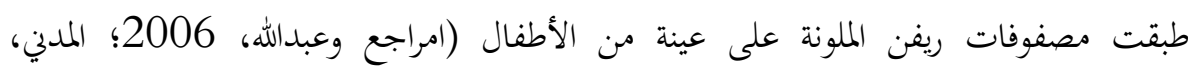

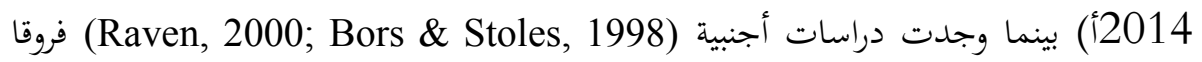

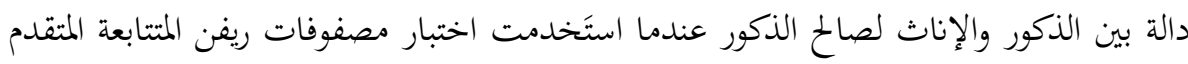

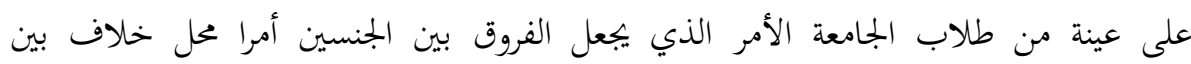

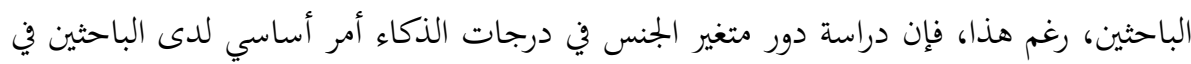

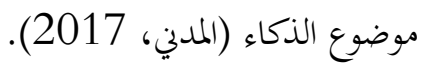

ومما يميز اختبارات ريفن للمصفوفات المتتابعة اعتمادها على إطار نظري واضح منذ أنساء نشأقها، حيث نشأت وتطورت في ظل نظرية العاملين لسبيرمان الذي يرى أن أفضل المقاييس التي

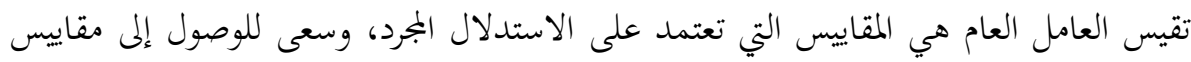

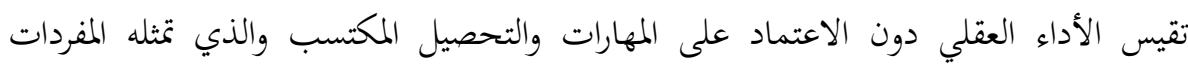
اللغوية، ومن هنا نشأت اختبارات ريفن كتطبيق لنظرية العاملين لسبيرمان. ويشير ريفن (Raven, 2000) إلى أن مصفوفات ريفن المتتابعة تقيس عنصرين أساسيين لنطين من القدرة العقلية العامة حسب اقتراح سبيرمان وهما: 1) القدرة على الاستنتاج Ability، وتعني القدرة على استخلاص معنى من الغموض -أو من الأشياء الغامضة، والقدرة على توليد مخططات عالية المستوى - غالبا غير لفظية- تجعل من السهل التعامل مع الأشياء

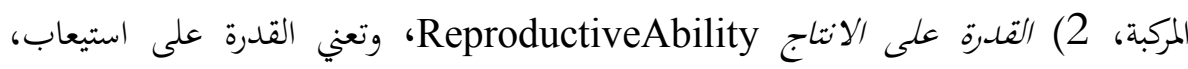

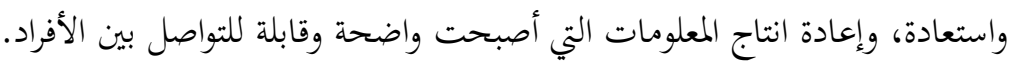

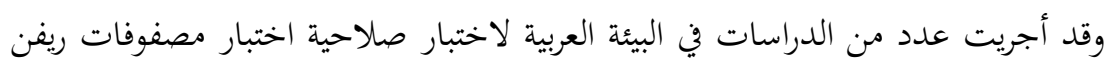

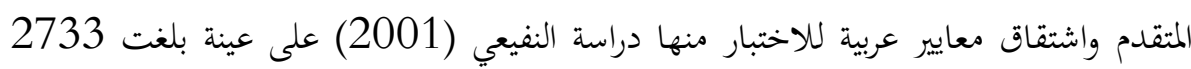

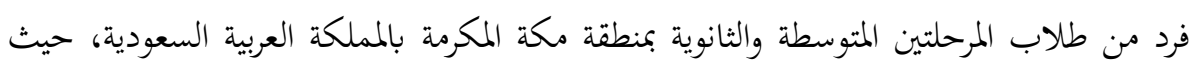

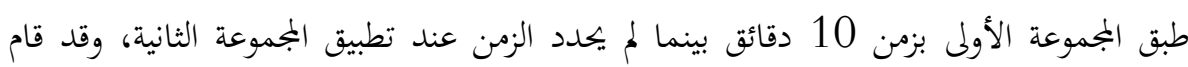

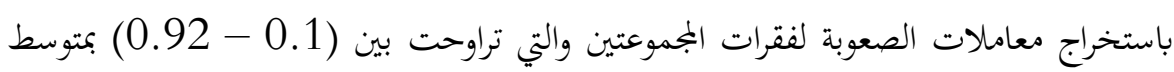


مقدار 0.58، ومعاملات التمييز التي تراوحت بين (0.10 - 0.65) بمتوسط مقداره

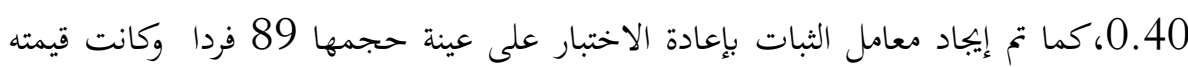

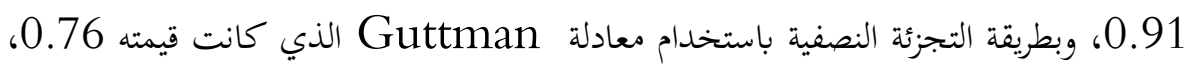
وكذلك ثبات الاتساق الداخلي باستخدام معادلة (KR-20) الذي كانت قيمته للعينة الكلية 0.84، أما دلائل الصدق فتم إيجادها من خلال المؤشرات الكمية لصدق التكوين

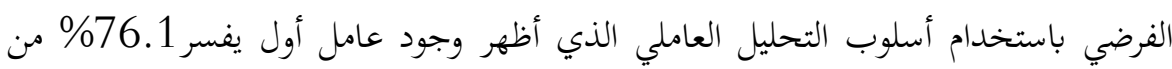

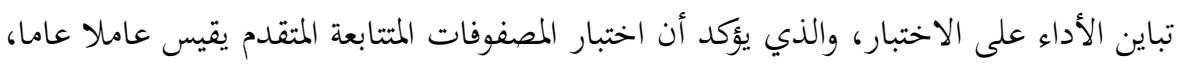

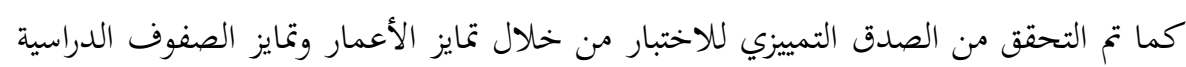

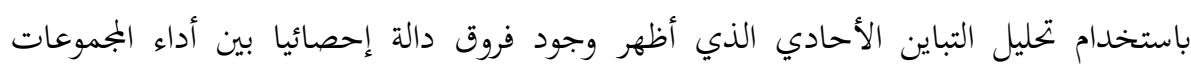
العمرية وكذلك بالنسبة للصفوف الدراسية.

ويعرض ابن زرقين (2016) دراسة للحارثي (2004) قنن فيها اختبار المصفوفات

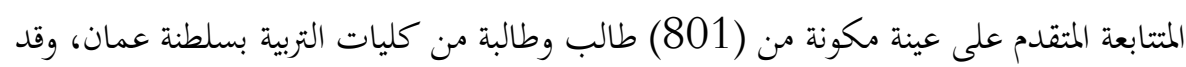

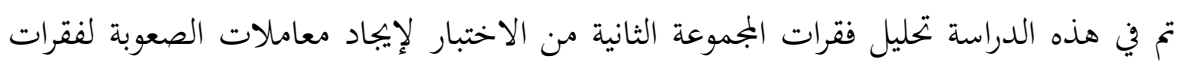

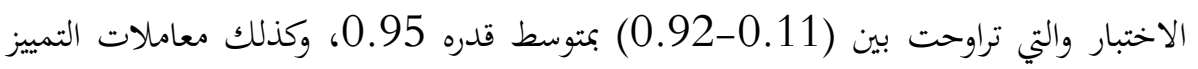

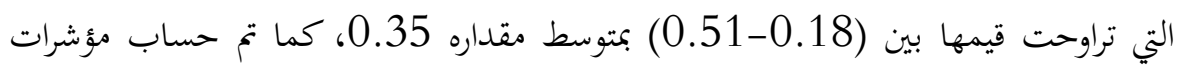
الثبات بإعادة الاختبار على عينة مكونة من 80 طالبا وطالبة وكانت قيمته 0.82 وكذا معامل معامل

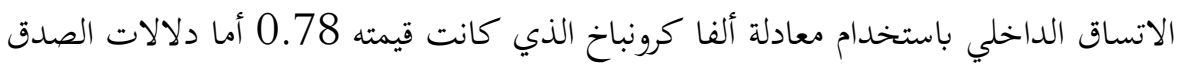

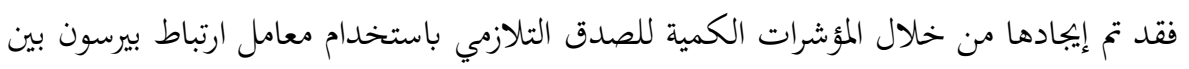

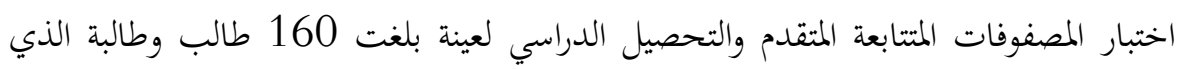

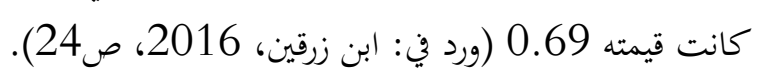
وفي دراسة أخرى قام إبراهيم وآخرون (2013) بدراسة تمدف فئ زإلى تقنين اختبار المصفوفات

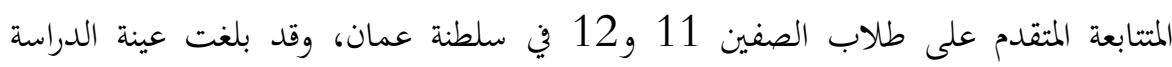
2467 طالب وطالبة (1199 ذكور و1268 إناث) ، وأظهرت النتائج مدى واسعا لمعاملات

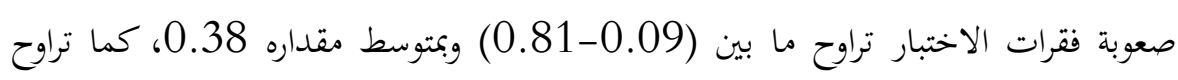

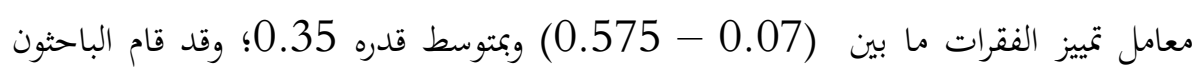


باختبار ثبات الاختبار باستخدام معامل الاتساق الداخلي ألفاكرونباخ والذي بلغ 0.87، كما

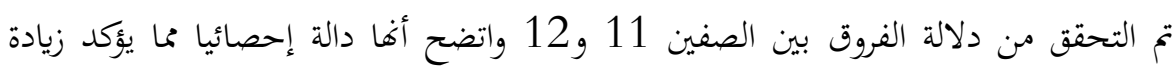
درجات الاختبار مع زيادة العمر وهو مؤشر لصدق التكوين الفرضي، كما تم إجراء التحليل العاملي التوكيدي للتحقق من البنية العاملية للاختبار وأكدت النتائج أن الاختبار أحادي البعد.

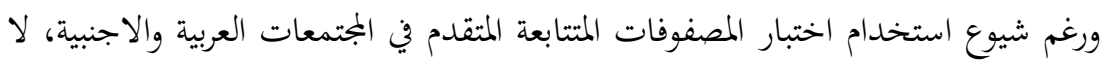

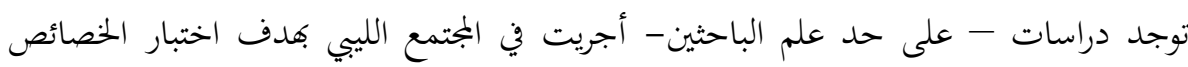

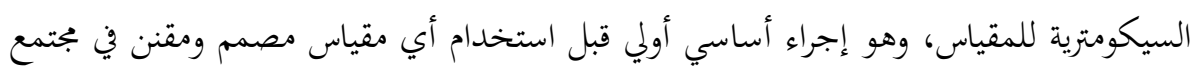

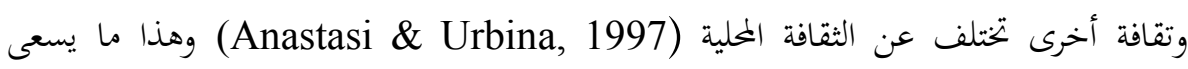
الباحثان إلى تحقيقه في هذا البحث، وبشكل محدد يهدف هذا البحث إلى الإجابة على الأسئلة التالية:

1) ماهي معدلات الصعوبة ومعاملات التمييز لفقرات اختبار المصفوفات المتتابعة المتقدم

$$
\text { على طلاب المرحلة الإعدادية والثانوية بمدينة مصراتة. }
$$

2) ما هي مؤشرات الصدق لاختبار المصفوفات المتتابعة المتقدم عند تطبيقه في مدينة مصراتة.

3) ما هي مؤشرات الثبات لاختبار المصفوفات المتتابعة المتقدم عند تطبيقه في مدينة مصراتة.

2.

\section{1 2 1 عينة البحث}

شملت عينة البحث على 400 طالب وطالبة من المتفوقين دراسياً بالمرحلة الاعدادية والثانوية من أربع مناطق جغرافية بمدينة مصراتة هي: طمينة، الزروق، ذات الرمال، المحجوب، الئل

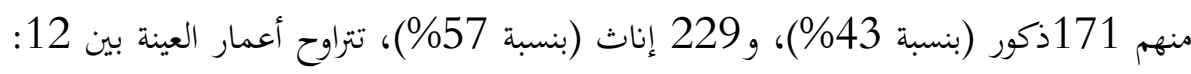

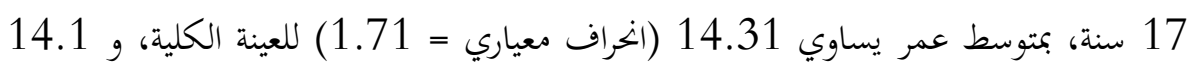

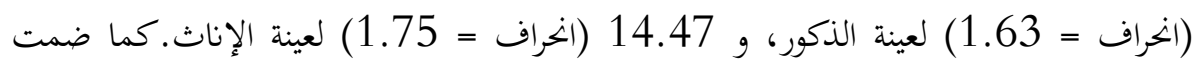
العينة أيضا عدد (100) طالب من غير المتفوقين (50 ذكور، و50 إناث ) تتراوح أعمارهم

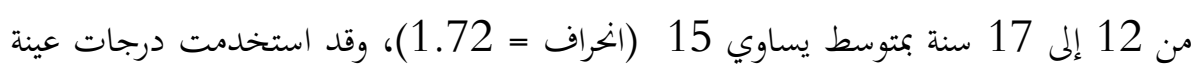
الطلاب غير المتفوقين لغرض حساب الصدق المحكي للاختبار. 
موضوع هذا البحث هو اختبار مصفوفات ريفن المتتابعة المتقدم من إعداد جون ريفن

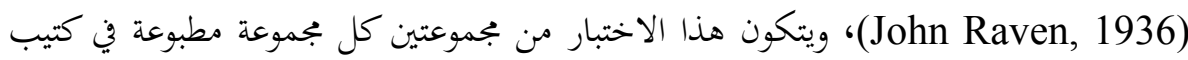

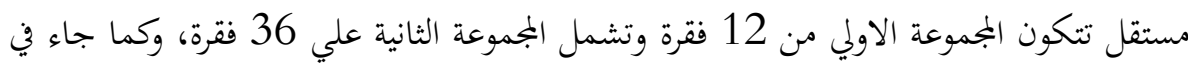

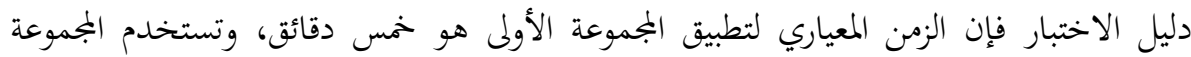
الأولى لتدريب المفحوص على الاختبار، أو كاختبار قصير يقسم الأفراد بموجبه إلى ثلاث الاث فئات:

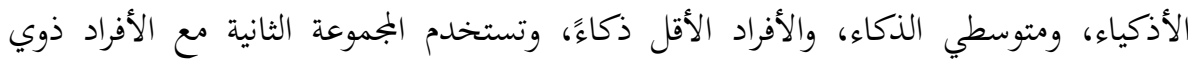

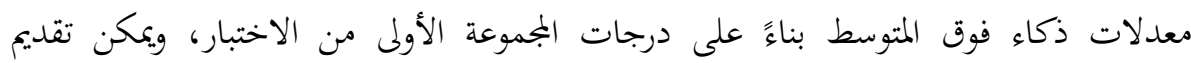
الاختبار دون تحديد زمن للتطبيق، أو بتحديد 40 دقيقة كزمن للتطبيق (Raven,2000). ويذكر إبراهيم وآخرون، (2013، ص. (Raven et al , 1998) أن تطبيق الاختبار في زمن محدد يقيس الكفاءة العقلية Intellectua Efficiency للفرد، وقدرته على إصدار أحكام سريعة ودقيقة حسب متطلبات الموقف، أما تطبيقه دون تحديد زمن فيقيس السعة العقلية العامة للفرد Intellectual Capacit وقدرة الفرد على الإدراك و ودقة الملاحظة والتفكير الواضح ·

وتتدرج فقرات الاختبار في صعوبتها، وتتكون كل فقرة من فقراته من تسعة أشكال

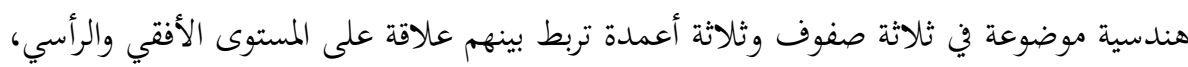

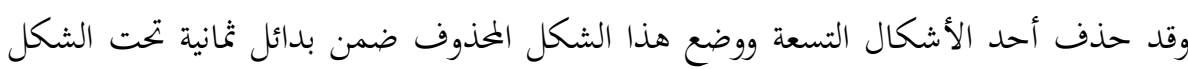
الأساسي، حيث يطلب من المفحوص في كل فقرة في الاختبار أن يتعرف على العنصر المفقود

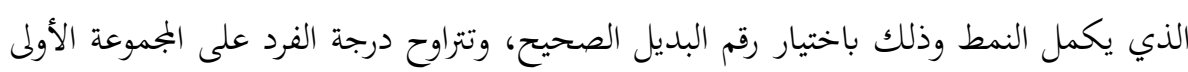

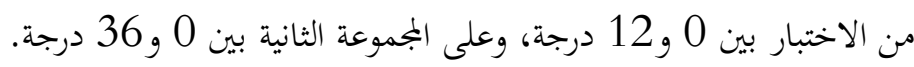
2. 3 إجراءات البحث آنبار لين

اختيرت عينة البحث الأساسية (ن=400) من خلال ثلاث خطوات، الأولى: تحديد المناطق التعليمية التي ستسحب منها العينة، وقد حددت بشكل مقصود أربع مناطق بمدينة

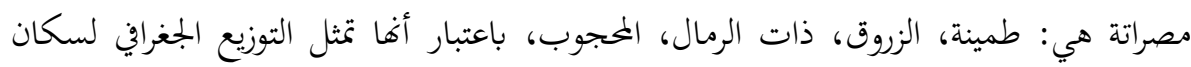

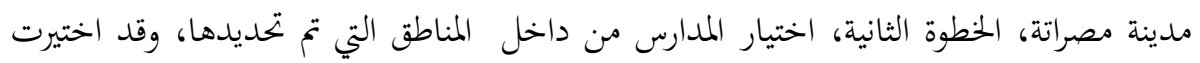


المدارس عشوائيا من قائمة المدارس الإعدادية والثانوية المعتمدة من مكتب القياس والتقويم

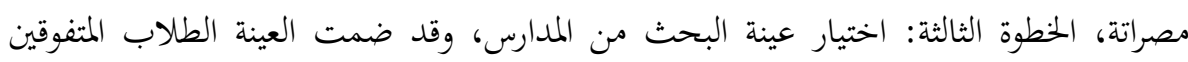
المتحصلين على التراتيب العشرة الأولى على مستوى المدرسة من كل سنة ديحت دراسية بالمرحلة

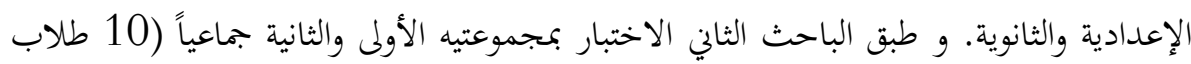

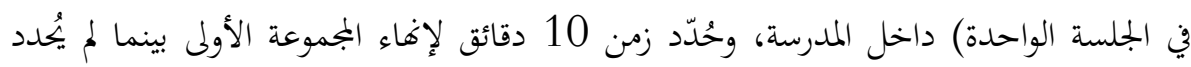
الزمن عند تطبيق المجموعة الثانية.

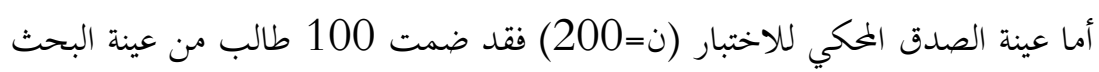
الأساسية (45 ذكور و 55 إناث) اختيروا من قائمة عينة البحث الأساسية بأسلوب العينة

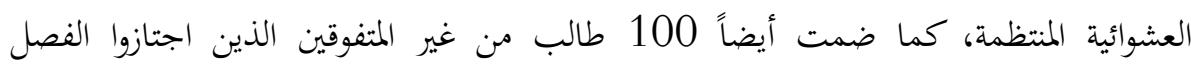

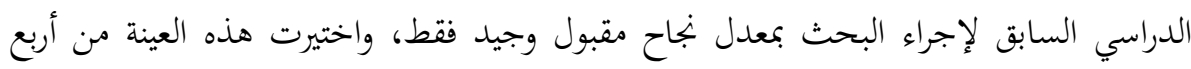
مدارس تقع وسط مدينة مصراتة. إحصائيا، استخدم الباحثان معامل النسب 1 و الاختبار التائي ومعامل ارتباط بيرسون،

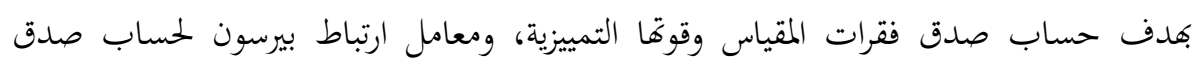

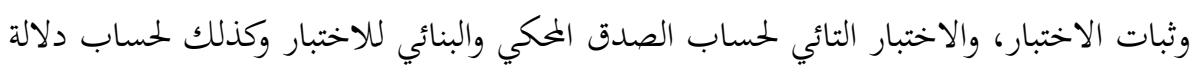
الفروق بين متوسط درجات عينة البحث وفقا لمتغير الجنس، و اختبار تحليل التباين ذي الإبحاه

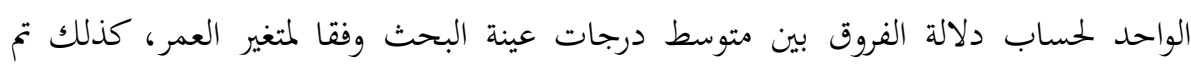

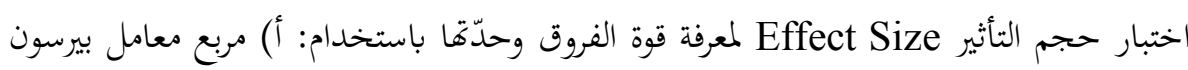

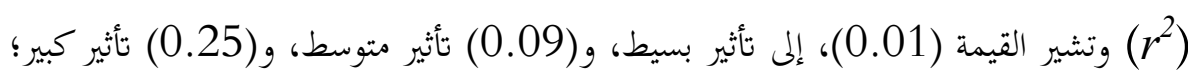

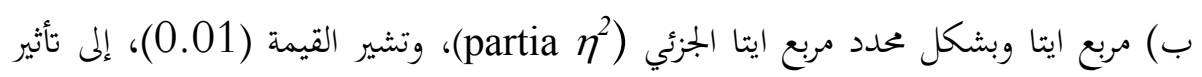
بسيط، و(0.06) تأثير متوسط، و(0.14) إلى تأثير كبير ( Nandy, 2012 (ب) ورد في: المدني، ن) 
3. - 3. النتائج ومناقشتها

\section{1 تحليل مفردات مصفوفات ريفن المتتابعة المتقدم واختبار صلاحية الفقرات:}

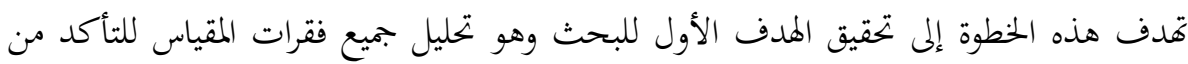

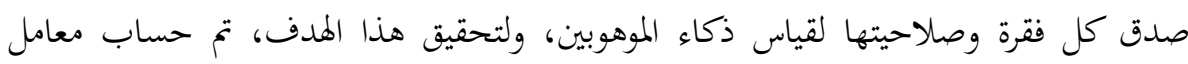

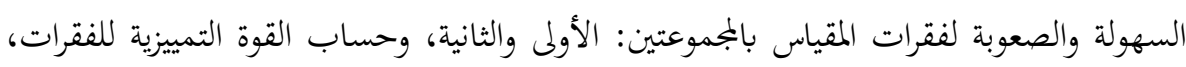
وارتباط كل فقرة بالدرجة الكلية للمقياس. 3. 1. 1 معامل الصعوبة لفقرات الإختبار تحدف هذه الخطوة إلى تحديد مدى صعوبة الفقرات بهدف التأكد من ترتيبها حسب الإحتبار

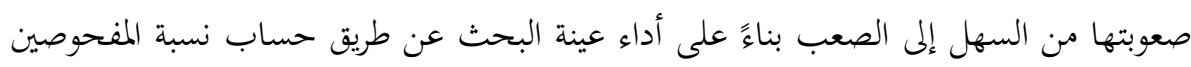

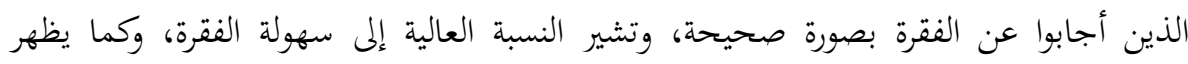

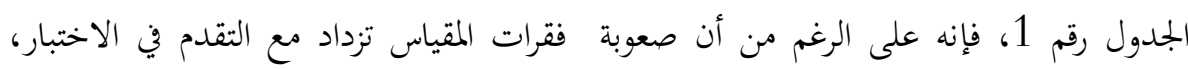

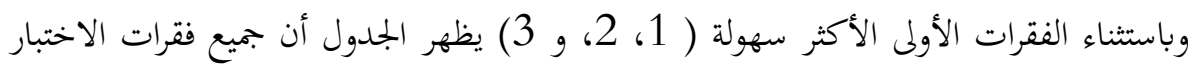

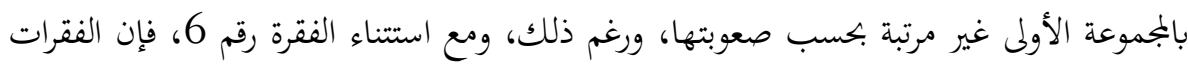

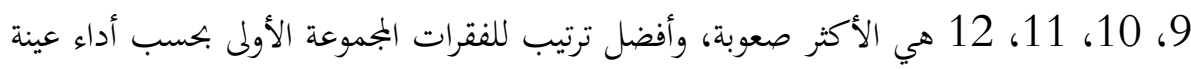

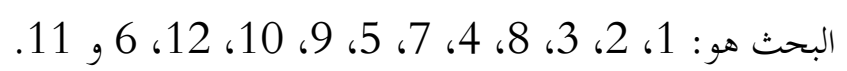

تراوحت درجات الاختبار بالمجموعة الأولى من 6 إلى 12 درجة بمتوسط يساوي

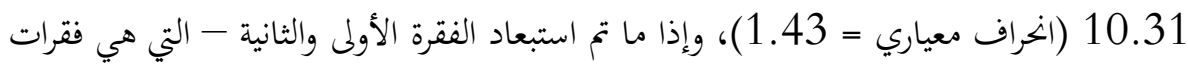

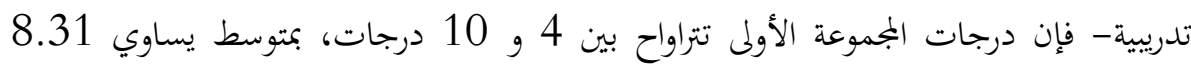
(انخراف معياري = 1.43)، وكما هو متوقع لاختبار مصمم لقدرات عقلية مختلفة، أظهر التمثيل

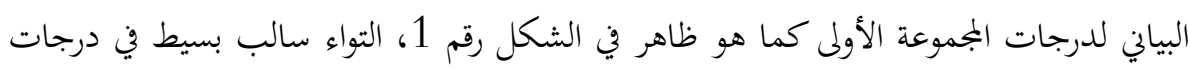

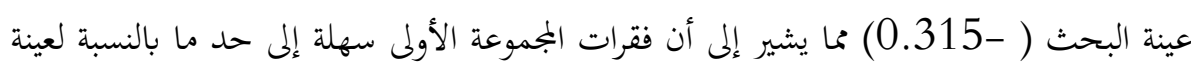

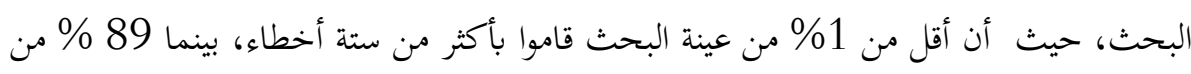

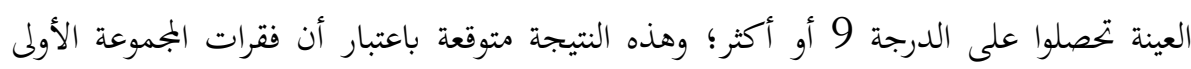

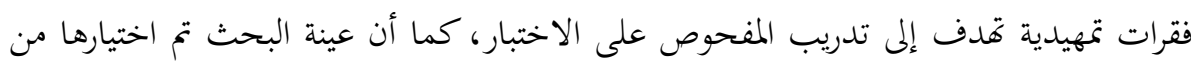

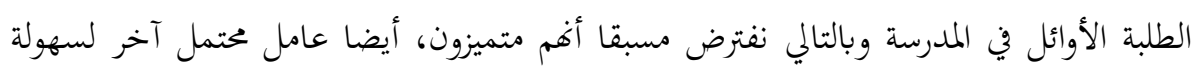


الجزء الاول بالنسبة لمجموعة البحث وهو أن الزمن الممنوح لإهماء الجزء الاول هو 10 دقائق بدل

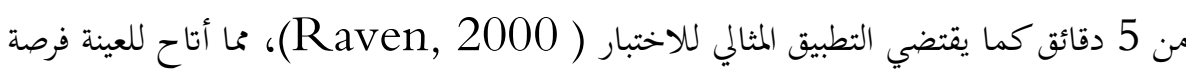
الإجابة على جميع فقرات الاختبار، الأمر الذي يسمح للباحثين بتحليل استجابة جميع الأفراد

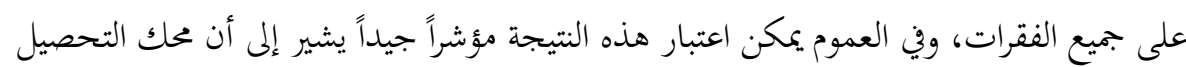
الدراسي الذي تم استخدامه لاختيار عينة البحث كان مناسباً. جدول 1 معامل صعوبة فقرات الاختبار للمجموعة الأولى والثانية

\begin{tabular}{|c|c|c|c|c|c|c|c|}
\hline \multicolumn{6}{|c|}{ المجموعة الثانية } & \multicolumn{2}{|c|}{ المجموعة الأولىى } \\
\hline الإجابة \% & الفقرة & الإجابة \% & الفقرة & الإجابة \% & الفقرة & الإجابة \% & الفقرة \\
\hline 84.8 & 25 & 99 & 13 & 100 & 1 & 100 & 1 \\
\hline 31 & 26 & 96 & 14 & 100 & 2 & 100 & 2 \\
\hline 32.3 & 27 & 95 & 15 & 78.8 & 3 & 91.8 & 3 \\
\hline 33.3 & 28 & 95.8 & 16 & 90.3 & 4 & 90.8 & 4 \\
\hline 16 & 29 & 95.8 & 17 & 95.3 & 5 & 89.3 & 5 \\
\hline 14.8 & 30 & 85 & 18 & 96.8 & 6 & 76.8 & 6 \\
\hline 18 & 31 & 85.5 & 19 & 96.6 & 7 & 90.3 & 7 \\
\hline 16 & 32 & 88.8 & 20 & 97 & 8 & 91 & 8 \\
\hline 16.3 & 33 & 88.5 & 21 & 95.3 & 9 & 87.5 & 9 \\
\hline 13.3 & 34 & 91.5 & 22 & 87.8 & 10 & 83 & 10 \\
\hline 12.3 & 35 & 91.5 & 23 & 96.8 & 11 & 53.3 & 11 \\
\hline 10 & 36 & 27.8 & 24 & 95.3 & 12 & 77.3 & 12 \\
\hline
\end{tabular}

كما يظهر الجدول رقم 1 أن فقرات الاختبار في المجموعة الثانية تظهر بشكل عام

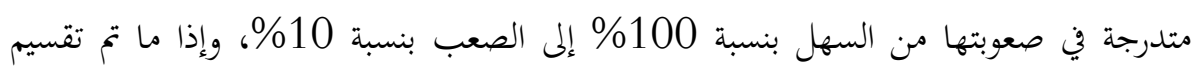

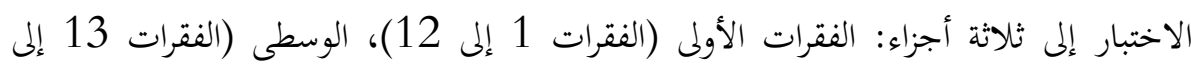

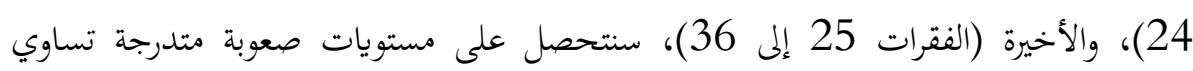

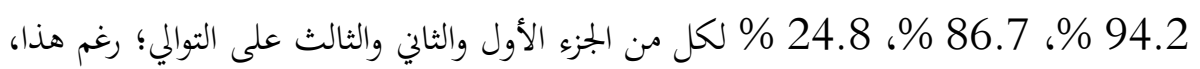

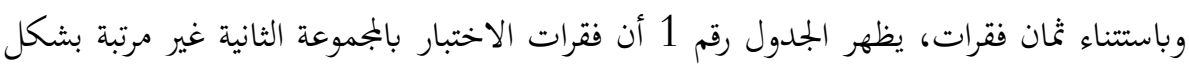

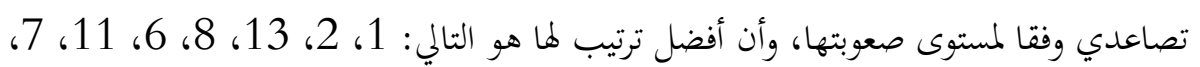




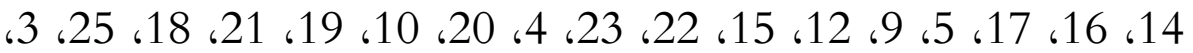
27، 28، 26، 24، 31، 33، 33، 29، 32، 30، 34، 35، 34 34،

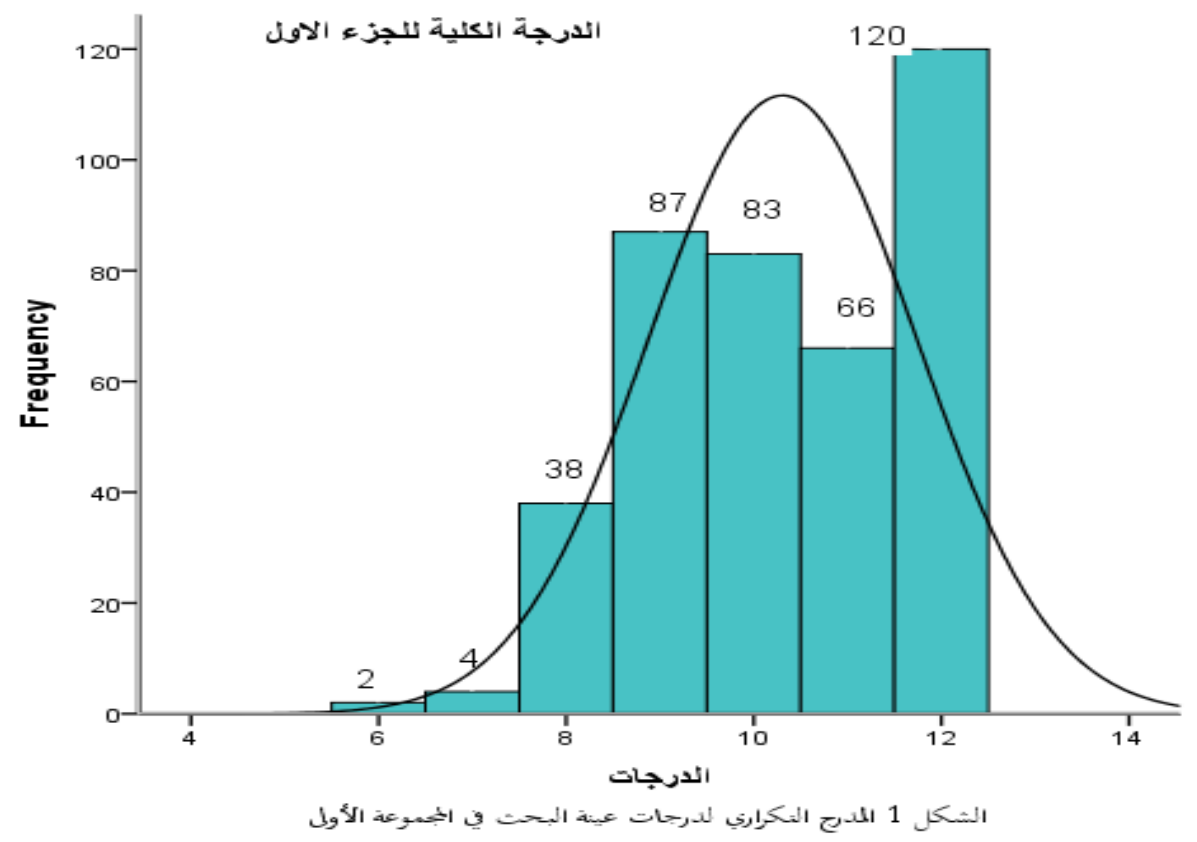

وتراوحت درجات الاختبار بالمجموعة الثانية من 16 إلى 33 درجة بمتوسط يساوي

24.67 (انحراف معياري = 3.25)، ويَظهر التوزيع التكراري لدرجات عينة تحليل المفردات

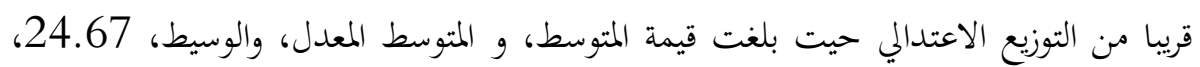

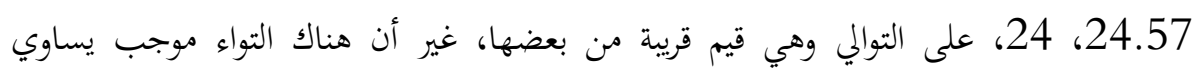

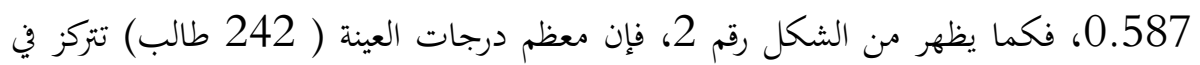

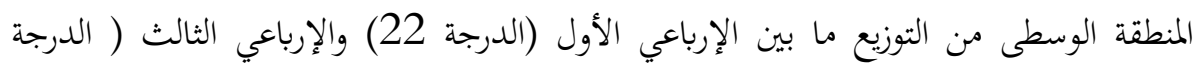

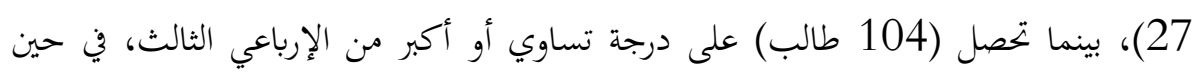
تحصل 54 طالب على درجة أقل من الإرباعي الأول، وهي نتيجة متوقعة من عينة تم الختيارها

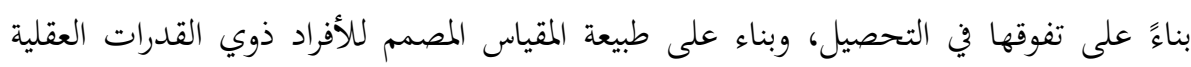
المتوسطة وفوق المتوسط. 


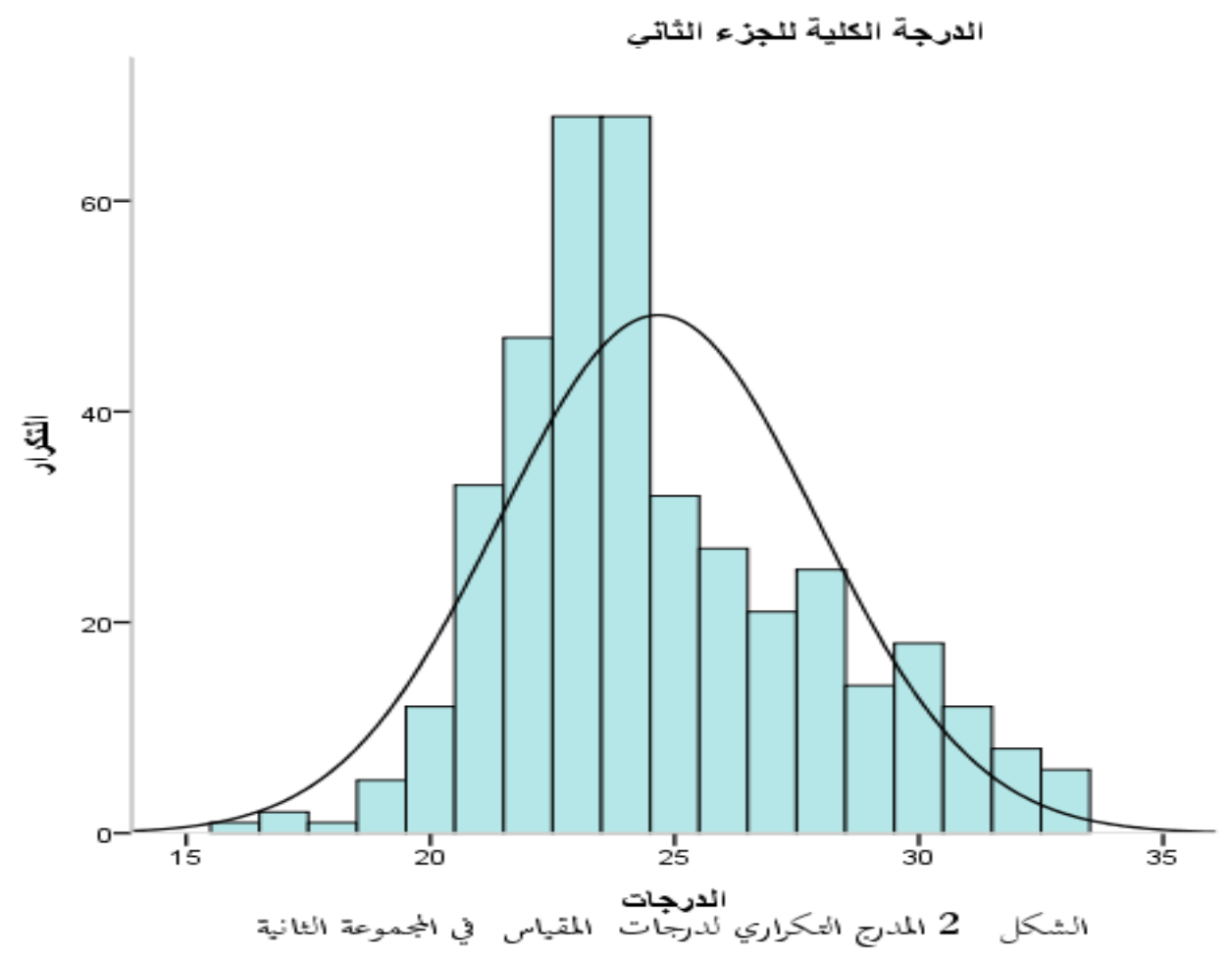

3. 1. 2 صدق فقرات مصفوفات ريفن المتتابعة المتقدم الجمموعة الثانية لاختبار صلاحية فقرات مصفوفات ريفن المتتابعة المتقدم المجموعة الثانية اعتمد الباحثان

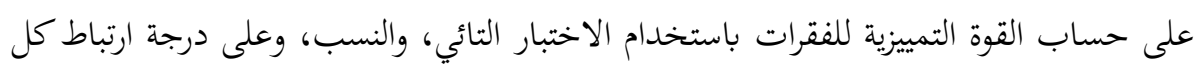
فقرة بالدرجة الكلية للمفحوص على الاختبار، ويقصد بالقوة التمييزية لفقرات قدرتا على التمبيز

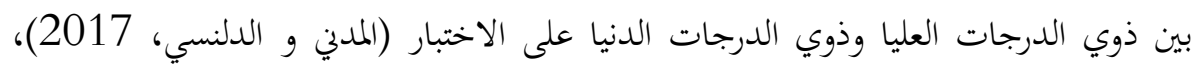
ولتحقيق ذلك استخدم الباحثان طريقة المجموعتين المتطرفتين التي تعتبرها أنستازي و أُربينا (Anastasi \& Urbina, 1997)

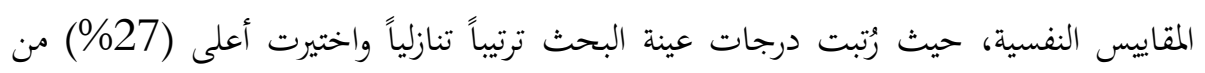

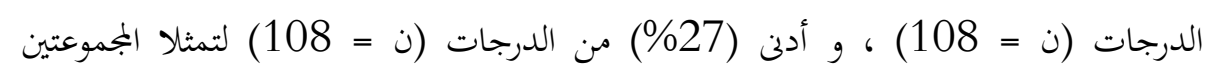
المتطرفتين. 
في هذا المجال، قام الباحثان باختبار دلالة الفروق بين متوسط درجات كل فقرة من فقرات

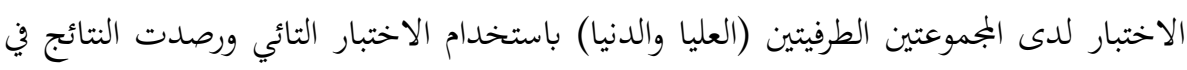
الجدول رقم (2). جدول رقم (2) معاملات تمبيز فقرات الاختبار المجموعة الثانية باستخدام الاختبار التائي م الدنيا م العليا

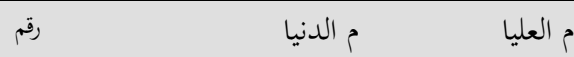
الفقرة

\begin{tabular}{|c|c|c|c|c|c|c|c|c|c|c|c|}
\hline قيمة ت & $\varepsilon$ & م & $\varepsilon$ & r & & قيمة ت & $\varepsilon$ & r & $\varepsilon$ & r & \\
\hline 4.801 & .48 & .65 & .29 & .91 & 19 & *. 1 & .10 & .99 & 0 & 1 & 1 \\
\hline 3.058 & .44 & .74 & .30 & .90 & 20 & *0 & 0 & 1 & 0 & 1 & 2 \\
\hline 5.765 & .44 & .74 & .10 & .99 & 21 & 3.64 & .48 & .63 & .37 & .84 & 3 \\
\hline 4.666 & .41 & .79 & .14 & .98 & 22 & 4.06 & .42 & .77 & .21 & .95 & 4 \\
\hline 5.972 & .43 & .75 & .00 & 1.0 & 23 & 3.99 & .34 & .87 & .00 & 1.0 & 5 \\
\hline 3.357 & .43 & .24 & .50 & .45 & 24 & 3.12 & .28 & .92 & .00 & 1.0 & 6 \\
\hline 3.908 & .47 & .68 & .32 & .89 & 25 & 2.1 & .29 & .91 & .16 & .97 & 7 \\
\hline 7.858 & .42 & .23 & .46 & .70 & 26 & 3.12 & .28 & .92 & .00 & 1.0 & 8 \\
\hline 4.886 & .45 & .29 & .49 & .60 & 27 & 2.09 & .32 & .89 & .19 & .96 & 9 \\
\hline 5.672 & .46 & .30 & .48 & .66 & 28 & 5.58 & .44 & .73 & .13 & .98 & 10 \\
\hline 8.094 & .19 & .04 & .50 & .45 & 29 & 3.30 & .29 & .91 & .00 & 1.0 & 11 \\
\hline 8.389 & .14 & .02 & .50 & .44 & 30 & 3.74 & .35 & .86 & .10 & .99 & 12 \\
\hline 10.38 & .14 & .02 & .50 & .54 & 31 & *1.42 & .00 & 1.0 & .14 & .98 & 13 \\
\hline 9.971 & .10 & .01 & .50 & .50 & 32 & 3.48 & .30 & .90 & .00 & 1.0 & 14 \\
\hline 9.617 & .13 & .02 & .50 & .50 & 33 & *1.34 & .29 & .91 & .21 & .95 & 15 \\
\hline 7.777 & .00 & .00 & .48 & .36 & 34 & 3.56 & .34 & .87 & .10 & .99 & 16 \\
\hline 7.904 & .10 & .01 & .49 & .39 & 35 & ${ }^{*} .80$ & .28 & .92 & .23 & .94 & 17 \\
\hline 7.467 & .00 & .00 & .48 & .34 & 36 & 4.06 & .45 & .72 & .26 & .93 & 18 \\
\hline
\end{tabular}

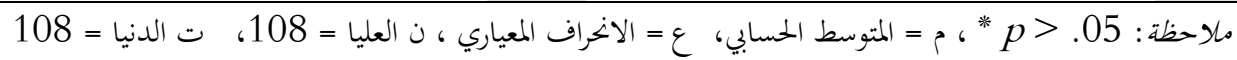

يُظهر الجدول رقم 2 فروقا ذات دلالة إحصائية بين متوسط درجات المجموعة العليا والدنيا على جميع فقرات الاختبار عدا الفقرات :1، 2، 13، 15، 15، و 17 17، وهي الفقرات الأولى من 
المجموعة الثانية من الاختبار وفقا للترتيب المقترح في هذه الدراسة، كما يظهر الجدول تقاربا بين

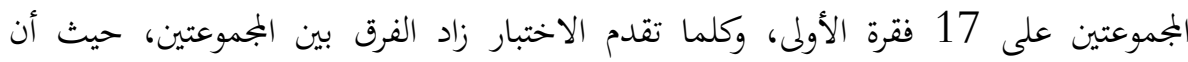

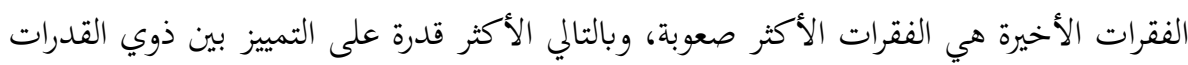
العقلية المرتفعة.

ويدعم هذه النتيجة اختبار القدرة التمييزية للفقرات باستخدام معامل النسب والتي رصدت نتائجة في الجدول رقم 3، حيث يظهر أن معظم فقرات الاختبار الأولى (17 فترة)

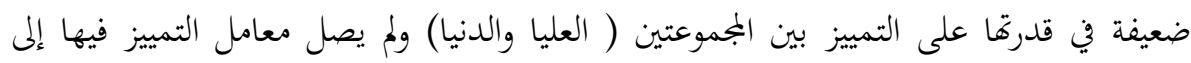
المعامل (0.19) وهو الحد الأدنى من معاملات التمييز المقبولة، بينما سجلت الفقرات الأخيرة (12 فقرة) أعلى معاملات تمييز بمتوسط يساوي (0.40))، وهو ما يتناسب مع طبيعة فقرات

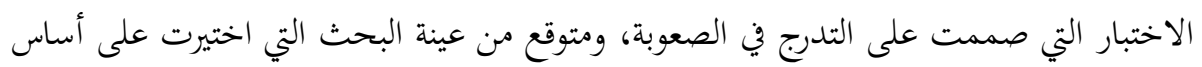
تفوقها في التحصيل الدراسي، فقد كان أداء عينة البحث متقاربا في الفقرات الأولى، وبدأ يظهر فئه

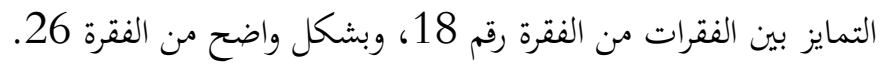

جدول (3 ) معاملات تمبيز فقرات ريفن المتتابعة المتتلدم المجموعة الثانية باستخدام النسب

\begin{tabular}{|c|c|c|c|c|c|c|c|c|c|c|c|c|}
\hline 12 & 11 & 10 & 9 & 8 & 7 & 6 & 5 & 4 & 3 & 2 & 1 & رقم الفقرة \\
\hline .99 & .1 & .98 & .96 & 1 & .97 & 1 & 1 & .95 & .84 & 1 & 1 & النسبة في العليا \\
\hline .86 & .91 & .73 & .89 & .92 & .91 & .92 & .87 & .77 & .63 & 1 & .99 & النسبة في الدنيا \\
\hline .13 & .09 & .25 & .07 & .08 & .06 & .08 & .13 & .18 & .21 & 0 & .01 & معامل التمييز \\
\hline 24 & 23 & 22 & 21 & 20 & 19 & 18 & 17 & 16 & 15 & 14 & 13 & رقم الفقرة \\
\hline .45 & .1 & .98 & .99 & .90 & .91 & .92 & .94 & .99 & .95 & .1 & .98 & النسبة في العليا \\
\hline .24 & .75 & .79 & .74 & .71 & .65 & .72 & .92 & .87 & .91 & .90 & 1 & النسبة في الدنيا \\
\hline .21 & .25 & .19 & .25 & .19 & .26 & .20 & .02 & .12 & .04 & .10 & .02 & معامل التمييز \\
\hline 36 & 35 & 34 & 33 & 32 & 31 & 30 & 29 & 28 & 27 & 26 & 25 & رقم الفقرة \\
\hline .34 & .39 & .36 & .50 & .50 & .54 & .44 & .45 & .66 & .60 & .70 & .89 & النسبة في العليا \\
\hline .00 & .01 & .00 & .02 & .01 & .02 & .02 & .04 & .30 & .29 & .23 & .68 & النسبة في الدنيا \\
\hline .34 & .38 & .36 & .48 & .49 & .52 & .42 & .41 & .36 & .31 & .47 & .21 & معامل التمييز \\
\hline
\end{tabular}


كما قام الباحثان بحساب معاملات التمييز باستخدام معامل الارتباط المصحح Corrected item-toal Correlation الاختبار، ويعد معامل الارتباط المصحح مقياس لدرجة تمييز الفقرة (إبراهيم وآخرون، 2013، ص. 48)، ورصدت النتائج في الجدول رقم 4.

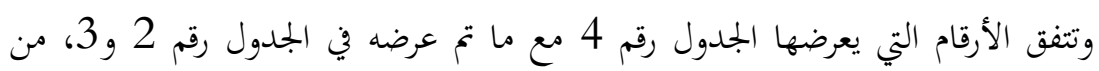
حيت أن معظم معاملات تمييز فقرات النصف الأول من الاختبار ضعيفة وكلما تقدم الاختبار

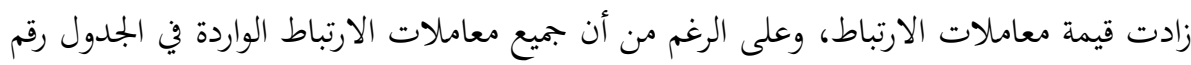

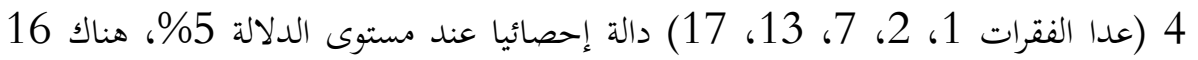

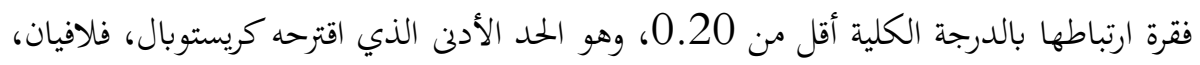
وجيناليو (Cristobal, Flavian, \& Guinaliu, M. 2007) لقبول معامل الارتباط المصحح في الدراسات الاستكشافية. ومع هذا فإن 20 فقرة من فقرات الاختبار (بنسار (بنسبة

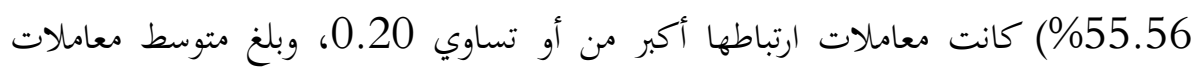

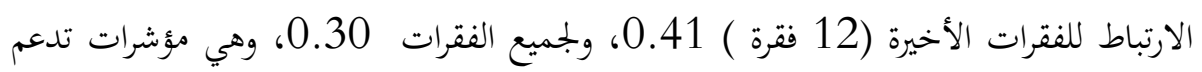

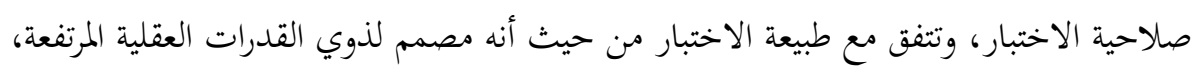
حيث تقل الفروق في بدايته وتزداد في فايته.

جدول (4) ملماملات تمييز فقرات ريفن المتتابعة المتقدم المجموعة الثانية باستخدام معامل الارتباط المصحح بين الفقرة والدرجة الكلية

\begin{tabular}{|c|c|c|c|c|c|c|c|c|c|c|c|c|}
\hline 12 & 11 & 10 & 9 & 8 & 7 & 6 & 5 & 4 & 3 & 2 & 1 & رقم الفقرة \\
\hline .23 & .11 & .25 & .12 & .17 & .*09 & .15 & 16 & .17 & .11 & $-* 07$ & $* 03$ & معامل الارتباط \\
\hline 24 & 23 & 22 & 21 & 20 & 19 & 18 & 17 & 16 & 15 & 14 & 13 & رقم الفقرة \\
\hline .21 & .26 & .25 & .26 & .10 & .18 & .14 & *.02 & .18 & *.04 & .20 & $-* 05$ & معامل الارتباط \\
\hline 36 & 35 & 34 & 33 & 32 & 31 & 30 & 29 & 28 & 27 & 26 & 25 & رقم الفقرة \\
\hline .48 & .46 & .42 & .50 & .56 & .52 & .46 & .43 & .31 & .29 & .40 & .20 & معامل الارتباط \\
\hline
\end{tabular}


3. 2 صدق مصفوفات ريفن المتتابعة المتقدم

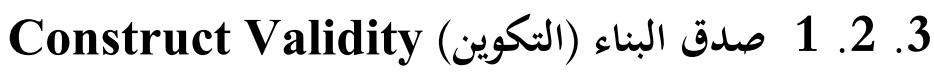

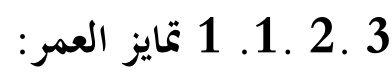

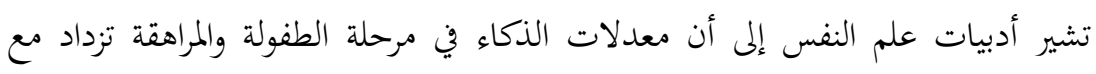

العمر ( فرج، 2011؛ Kaufman \& Lichtenberger, 2002 )، وبناء على ذلك، إنكاء

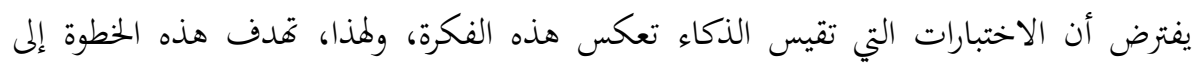

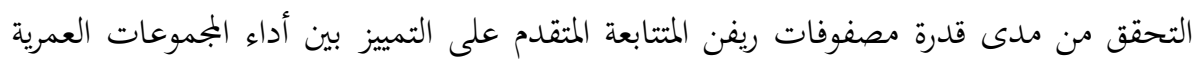

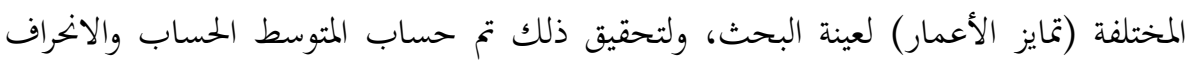

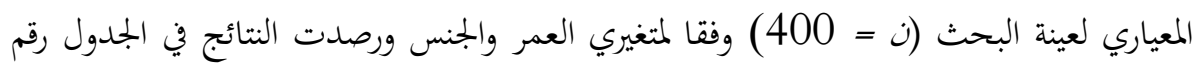

جدول قم 5 المتوسط والانراف المعياري لعينة البحث على مصفوفات ريفن المتقدم وفقا لمتغيري

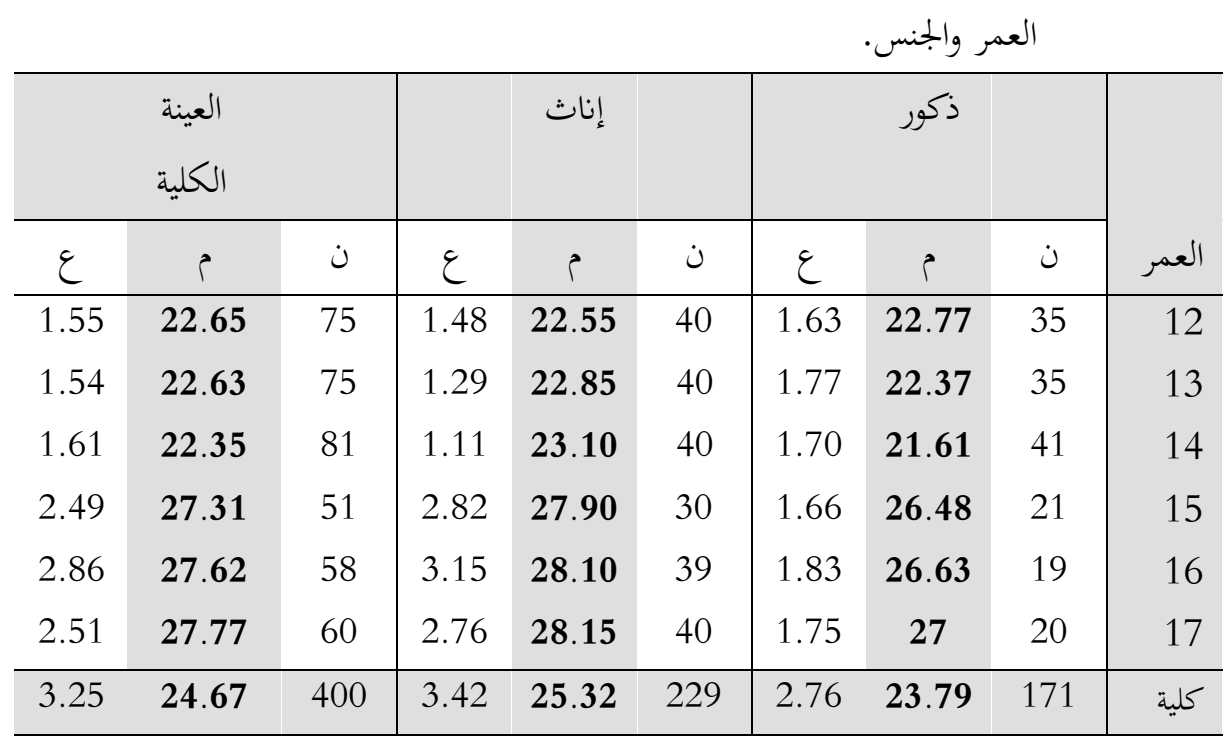

ملاحظة: م = المتوسط الحسابي، ع= الانخراف المعياري، ن = العدد

يظهر الجدول رقم 5 تمايز المجموعات العمرية في معدلات الذكاء لدى كل من الذكور

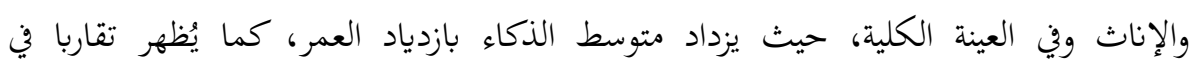




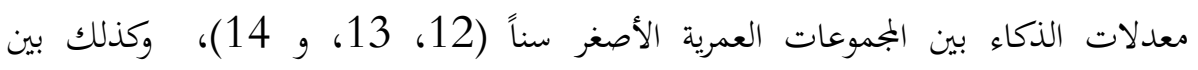

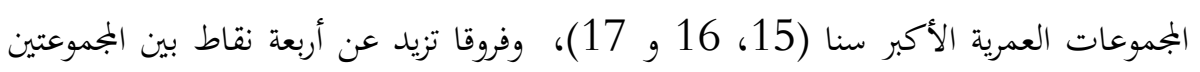

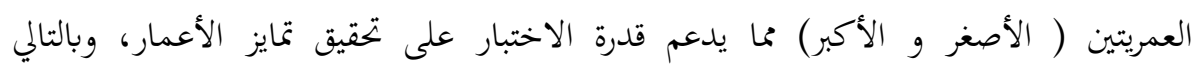

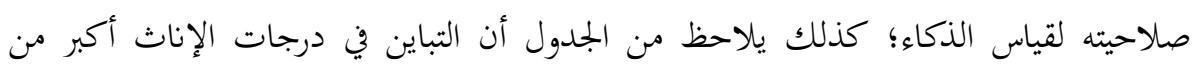

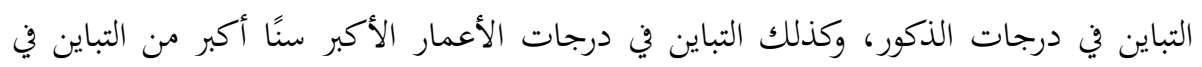

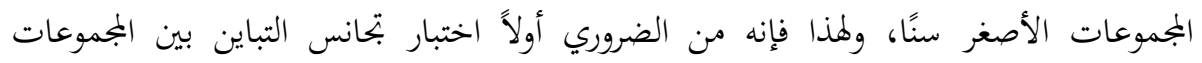
لتحديد إمكانية استخدام الإحصاء البارمتري.

ولاختبار بتانس التباين بين المجموعات وفقا لمتغيري العمر والجنس، تم استخدام الباتيات

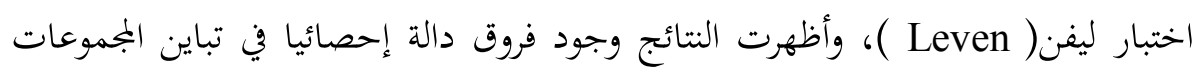

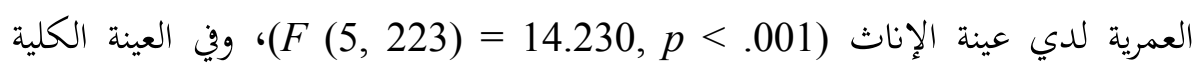

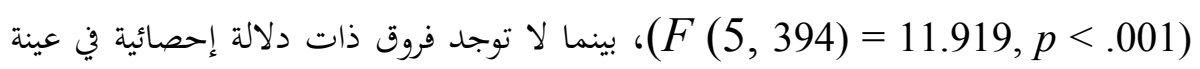
الذكور (F (5, 165) =0.163,p= تحليل التباين أحادي الاتحاه One-Way ANOVA لاختبار دلالة الفروق بين درجات

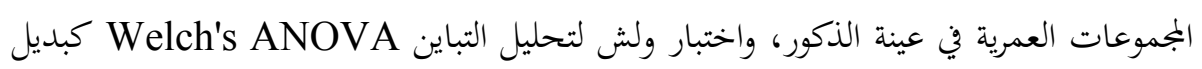
عن تحليل التباين أحادي الابتحاه لاختبار دلالة الفروق في عينة الإناث والعينة الكينة الكلية.

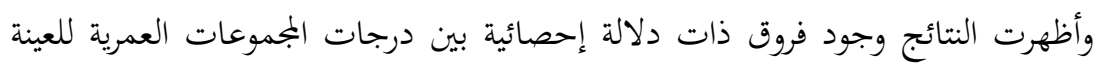

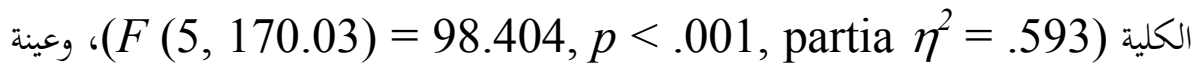
الإناث (58.

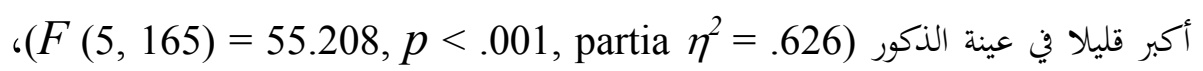
ولتحديد أي الفروق بين الجموعات العمرية تكون دالة إحصائيا، استخدم الباحت اختبات التبارات

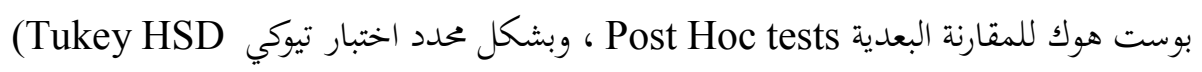

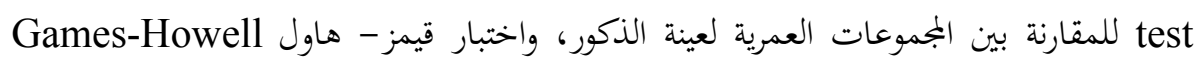

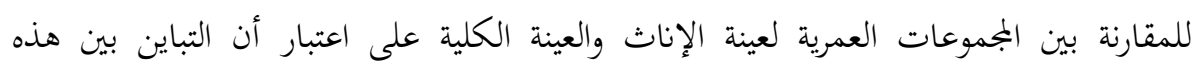

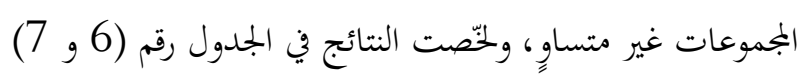


جدول رقم 6 متوسط الفروق بين المجموعات العمرية على مصغوفات ريفن المتقدم وفقا لمتغير

\begin{tabular}{|c|c|c|c|c|c|c|c|}
\hline 17 & 16 & 15 & 14 & 13 & 12 & العمر & \multirow[b]{2}{*}{ العينة } \\
\hline \multicolumn{7}{|c|}{ الإناث } & \\
\hline$-5.60^{*}$ & $-5.55^{*}$ & $-5.35^{*}$ & -.55 & -.30 & & 12 & \\
\hline$-5.30^{*}$ & $-5.25^{*}$ & $-5.05^{*}$ & -.25 & & -.40 & 13 & \\
\hline$-5.05^{*}$ & $-5.00^{*}$ & $-4.80^{*}$ & & -.76 & $-1.16^{*}$ & 14 & الذكور \\
\hline-.25 & -.20 & & $4.87^{*}$ & $4.10^{*}$ & $3.70^{*}$ & 15 & \\
\hline-.05 & & .16 & $5.02^{*}$ & $4.26^{*}$ & $3.86^{*}$ & 16 & \\
\hline & .37 & .52 & $-5.39^{*}$ & $4.63^{*}$ & $4.23^{*}$ & 17 & \\
\hline
\end{tabular}

جدول رقم 7 متوسط الفروق بين المجموعات العمرية على مصغوفات ريفن المتقدم للعينة الكلية

\begin{tabular}{|c|c|c|c|c|c|c|}
\hline 17 & 16 & 15 & 14 & 13 & 12 & العمر \\
\hline & & & & & -.027 & 13 \\
\hline & & & & -.281 & -.308 & 14 \\
\hline & & & $4.96^{*}$ & $4.68^{*}$ & $4.66^{*}$ & 15 \\
\hline & & .31 & $5.27^{*}$ & $4.99^{*}$ & $4.96^{*}$ & 16 \\
\hline & .15 & .45 & $5.42^{*}$ & $5.14^{*}$ & $5.11^{*}$ & 17 \\
\hline
\end{tabular}

ويُستخلص من الجدول رقم 6 و7 أن الفروق ذات الدلالة الإحصائية هي تلك الفروق

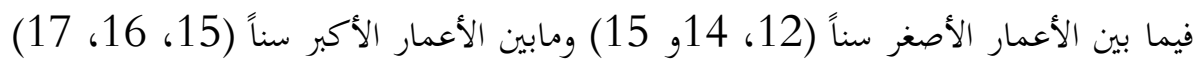

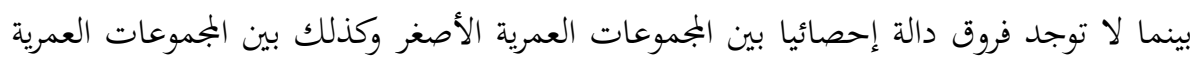

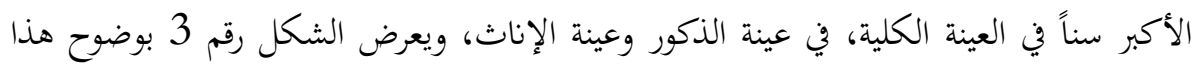
الفروق بين المجموعات العمرية. 


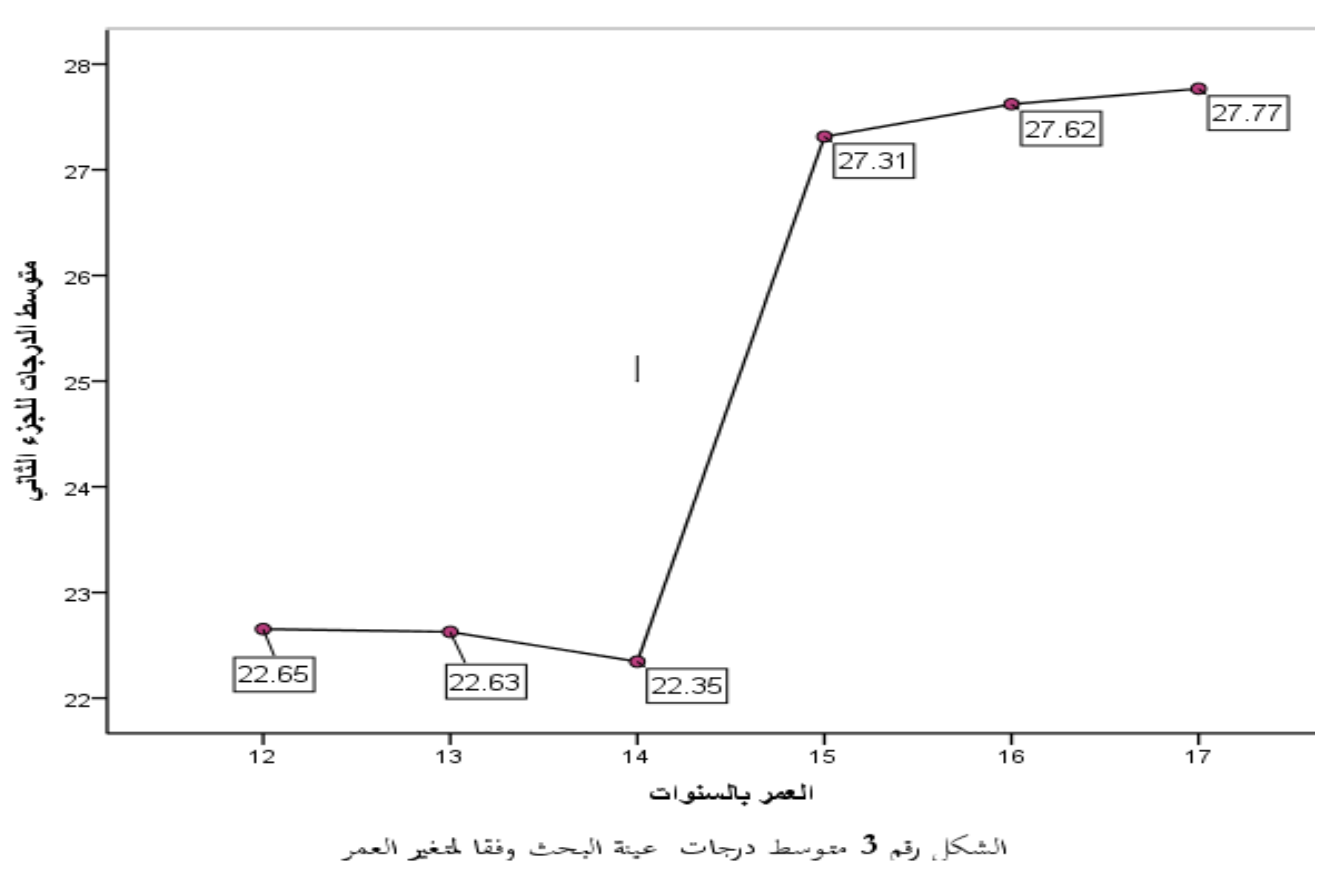

Group Differences 1.2. 1 1. 1 الفروق بين الجمموعتين الطرفيتين من مؤشرات الصدق البنائي للاختبار النفسي قدرته على التمييز بين من يكون أداؤهم

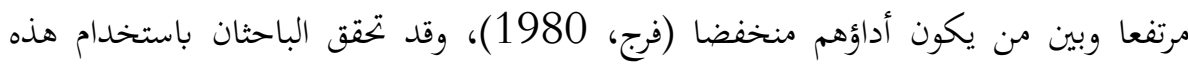
الطريقة من الصدق البنائي لمصفوفات ريفن المتقدم من خلال تطبيق الاختبار التائي على عينة البحث (N=400) وفقا لمتغيري العمر والجنس لمعرفة دلالة الفروق بين متوسط درجات

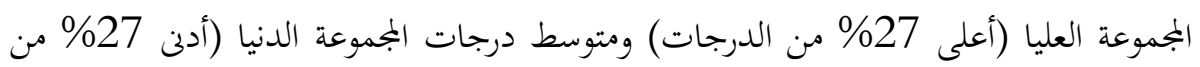

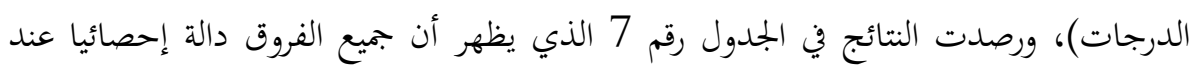

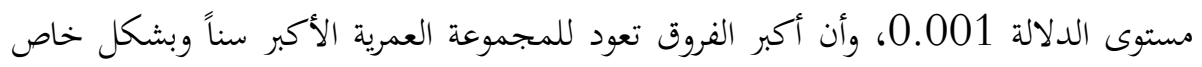

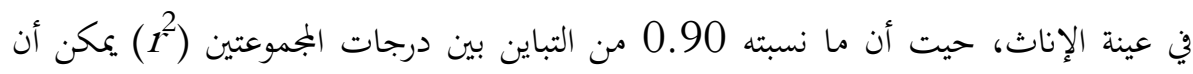

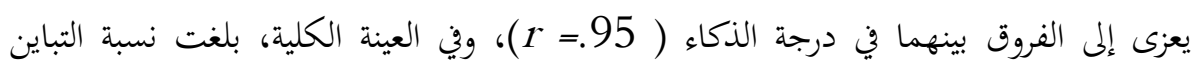

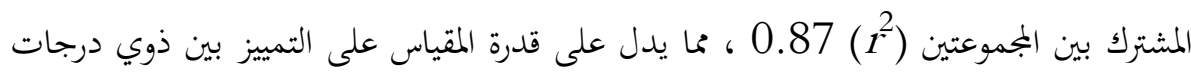

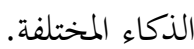


جدول رقم 8 المتوسط والانحرف المعياري للمجموعتين الطرفيتين على مصغوفات ريفن المتقدم

وفقا لمتغيري العمر والجنس.

\begin{tabular}{|c|c|c|c|c|c|c|c|c|c|c|}
\hline \multirow[b]{2}{*}{$r$} & \multicolumn{2}{|c|}{ الاختبار التائي } & \multicolumn{3}{|c|}{ البمموعة الدنيا } & \multicolumn{3}{|c|}{ المجموعة العليا } & \multirow[b]{2}{*}{ المتغير } & \multirow[b]{2}{*}{ العمر } \\
\hline & $\begin{array}{c}\text { df } \\
\text { درجة الحرية }\end{array}$ & قيمة t & الانمراف & المتوسط & العدد & الانحراف & المتوسط & العدد & & \\
\hline .88 & $42.04^{a}$ & $14.20 *$ & 1.40 & 20.10 & 30 & .681 & 24.13 & 30 & دكور & $\stackrel{\sim}{\sim}$ \\
\hline .89 & $40.17^{a}$ & $15.68 *$ & 1.02 & 21.16 & 32 & .397 & 24.19 & 32 & إناث & $\ddot{m}$ \\
\hline .88 & $77.13^{\mathrm{a}}$ & $21.71 *$ & 1.25 & 20.55 & 62 & .459 & 24.23 & 62 & الكلية & $\stackrel{\Xi}{\sqcup}$ \\
\hline .92 & 30 & 13.26 * & .775 & 24.75 & 16 & .998 & 28.94 & 16 & ذكور & 10 \\
\hline .95 & 58 & $23.61 *$ & 1.30 & 24.40 & 30 & 1.01 & 31.50 & 30 & إناث & $\stackrel{0}{\longleftarrow}$ \\
\hline .94 & 90 & $27.02 *$ & 1.15 & 24.52 & 46 & 1.13 & 30.96 & 46 & الكلية & 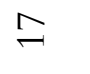 \\
\hline .93 & $186.47^{a}$ & $36.29 *$ & 1.25 & 21.21 & 108 & 1.88 & 29.10 & 108 & & الك الك \\
\hline
\end{tabular}

ملاحظة: تشير a إلى أن التباين في المجموعتين غير متجانس، وتم استخدام اختبار ولتش Welch $t$ test بدلا من

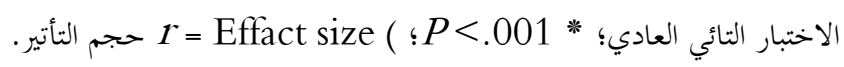

\section{Criterion Validity 3. 2. 2. 1 2. 1 محك التحصيل الدراسي}

يُعِرِ كل من كوفمان ويشتينبيرغ (Kaufman, \& Lichtenberger 2002) إلى أن الارتباط بين درجات الذكاء والتحصيل الدراسي تعد من أفضل الأدلة على صدق التصنين اختبارات

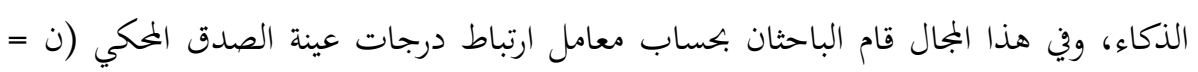

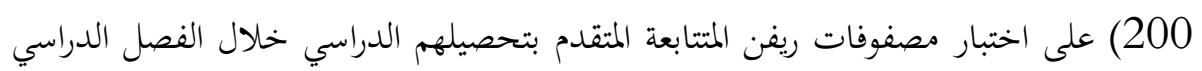

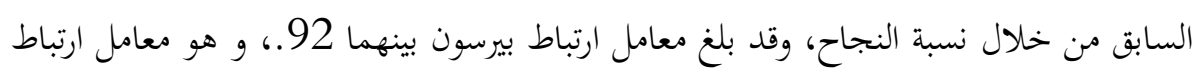

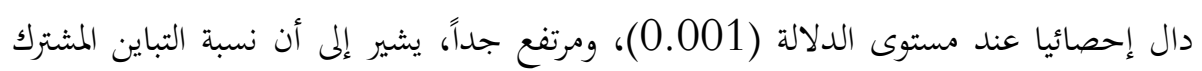
بين المتغيرين (r) 


\section{$\square$ Contrasted Group 3. 2. 2. 2 2حك الجمموعات المتباينة}

قام الباحثان بتطبيق اختبار ريفن المتقدم على عينة الطلاب غير المتفوقين (ن= 100)،

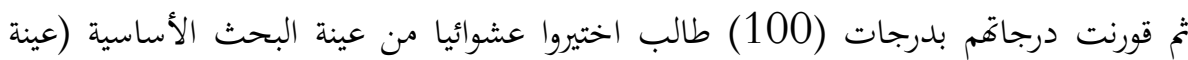

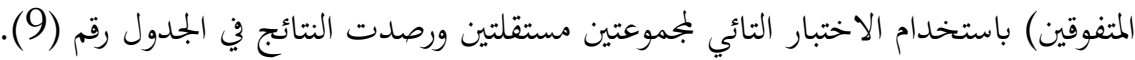
جدول (9) حساب دلالة الفروق بين أداء عينة الطلاب المتنوقين وغير المتنوقين

\begin{tabular}{|c|c|c|c|c|c|}
\hline قيمة t المحسوبة & درجة الحرية & الانحراف المعياري & المتوسط & العدد & \\
\hline \multirow[t]{2}{*}{38.480} & \multirow[t]{2}{*}{198} & 3.52 & 6.03 & 100 & الطلاب المتفوقون \\
\hline & & 3.33 & 24.67 & 100 & الطلاب غير المتفوقين \\
\hline
\end{tabular}

ويظهر الجدول رقم (9) وجود فروق ذات دلالة إحصائية عند مستوى الدلالة 001

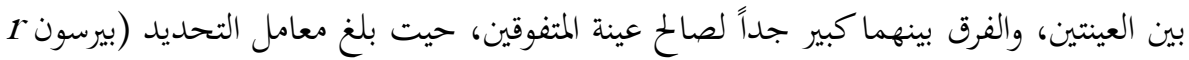

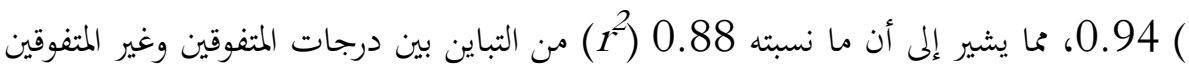
يمكن أن يعزى إلى الفروق بينهما في الذكاء، وهي نسبة عالية جداً تدعم صدق الاختبار وقدرته على تمييز الأفراد ذوي القدرات العقلية العالية.

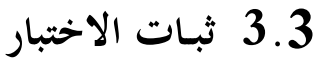

لحساب ثبات الاختبار قام الباحثان بحساب معامل استقرار الاختبار عن طريق التطبيق

وإعادة التطبيق، وحساب التجانس الداخلي باستحدام معامل الفاكرونباخ.

\subsection{1 طريقة التطبيق وإعادة التطبيق}

لحساب معامل استقرار الاختبار قام الباحثان بإعادة تطبيق المقياس بعد أسبوعين من إدهيو

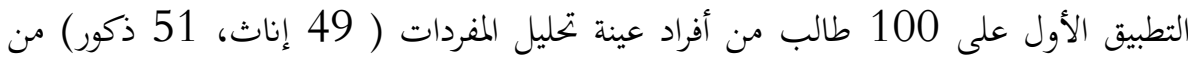
منطقة المحجوب وذات الرمال بمدينة مصراتة، وتراوحت أعمارهم بين 12 و و17 عاما، بمتوسط

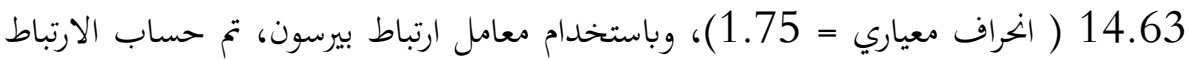

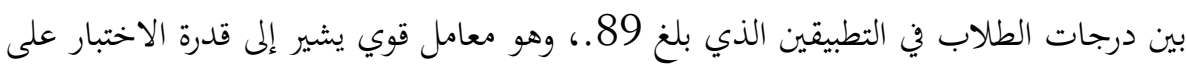

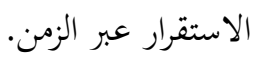




\section{Cronbach's alpha 2 معامل الفاكرونباخ}

يعد معامل ألفا كرونباخ من أكثر طرق التجانس الداخلي شيوعا في حساب ثبات

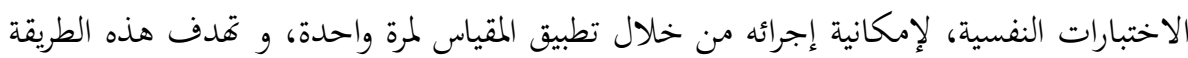

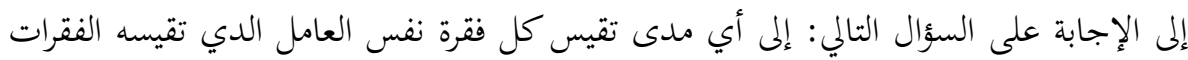

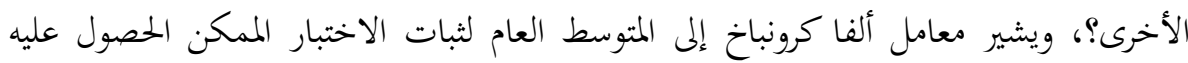

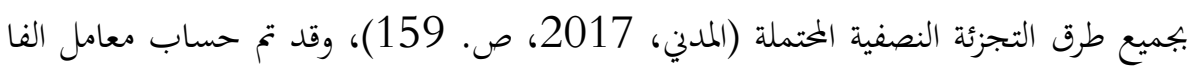
لمصفوفات ريفن المتقدم على عينة الثبات (100= دليل جيد على ثبات مصفوفات ريفن المتقدم في البيئة المحلية. ولعل الخفاض قيمة معامل التجانس (70.) على قيمة معامل الاستقرار (89. (89) يعود

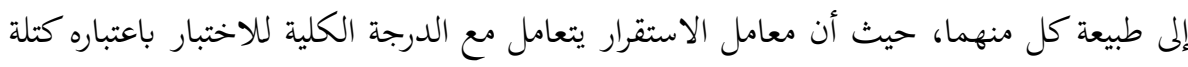
واحدة، وبالتالي لا يؤثر وجود بعض الفقرات غير المرتبطة بباقي الفقرات أو الدرجة الكلية -

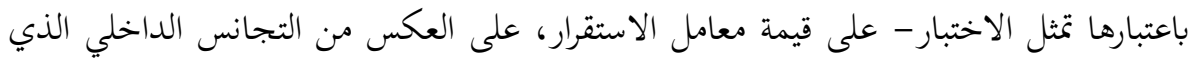

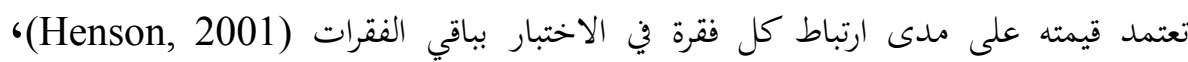
وباعتبار أن معامل ارتباط الفقرات الأولى من اختبار ريفن المتقدم بالدرجة الكلية ضعيفة (انظر فئرة جدول رقم 4) انخفض تبعاً لذلك معامل ألفاكرونباخ.

4. الخالاصة والتوصيات

يعد اختبار مصفوفات ريفن المتتابعة المتقدم من اختبارات الذكاء المتحررة من أثر الثقافة

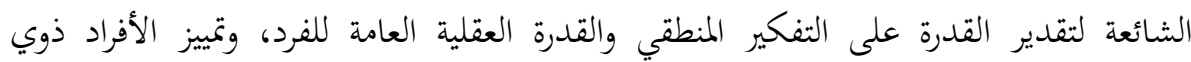

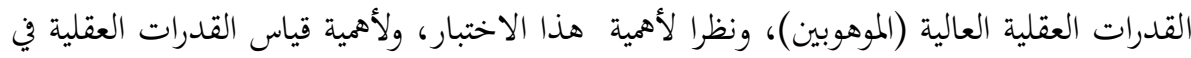
الميدان التعليمي بشكل عام، أجري هذا البحث لاختبار الخصائص السيكومترية لاختبار

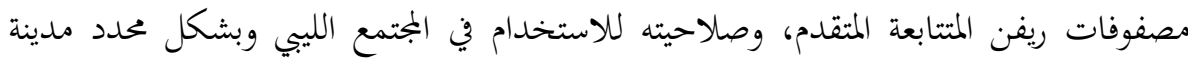

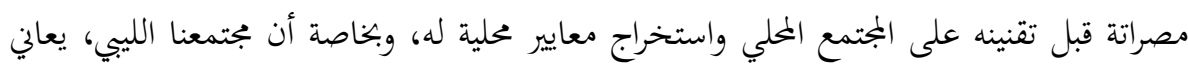
فيه العاملون في الميدان التعليمي من ندرة اختبارات القدرات العقلية الموثوقة التي تعينهم في ولئي

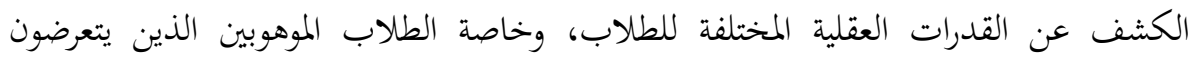

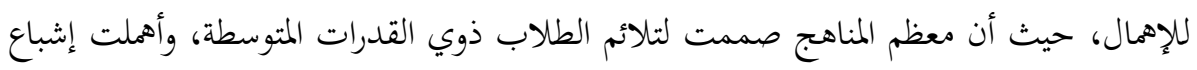


حاجات الطلاب الموهوبين، وتنمية إبداعهم وتفوقهم، لهذا، يأتي هذا البحث مساهمة في توفير

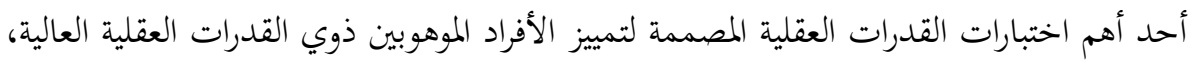
من خلال العمل على إعداد اختبار مصفوفات ريفن المتتابعة المتقدم للاستخدام في مدينة مصراتة، وتحليل فقراته، واختبار صلاحيته محلياً.

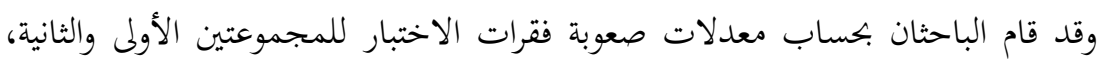

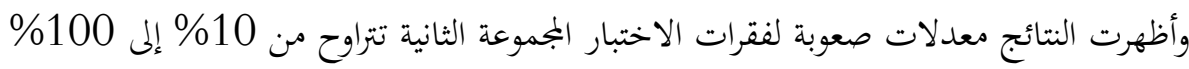
(68.56\%)، وبيَّن التحليل الإحصائي أن فقرات الاختبار غير مرتبة تصاعديا، لهذا اقترح

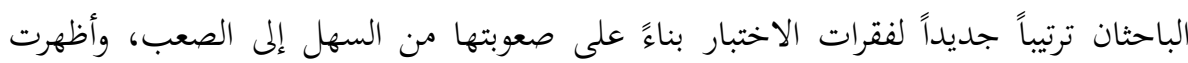

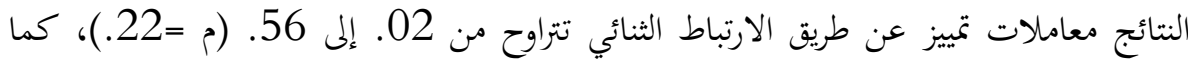
أظهر الاختبار مؤشرات قوية على صدقه من خلال قدرته على تحقيق تمايز المجموعات العمرية في

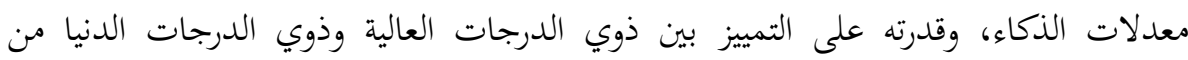

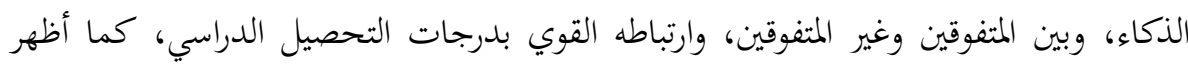
المقياس مؤشرات قوية للثبات من خلال اختبار الاستقرار عبر الزمن، واتساقه الداخلي.

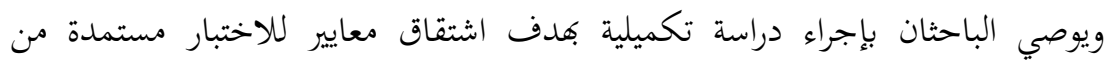

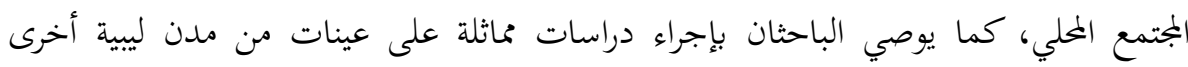
ومقارنة نتائج هذه الدراسات لمعرفة مدى إمكانية توحيد معايير الاختبار على كامل المجتمع اللببي.

\section{قائمة المراجع}

أولا: المراجع العربية:

إبراهيم، على محمد؛ كاظم، على مهدي؛ النبهاني، هلال زاهر؛ الجمالي، فوزية عبدالباقي

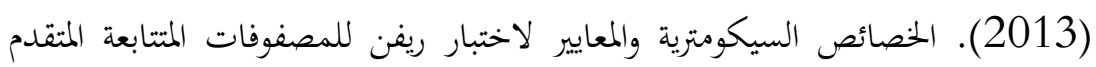

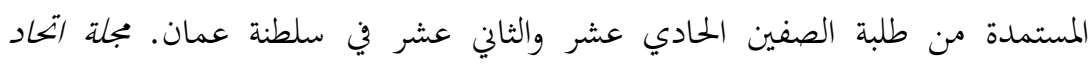

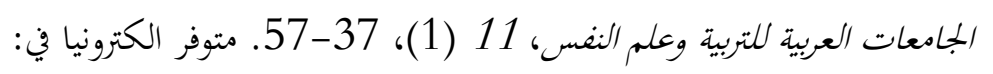

http://search.shamaa.org/PDF/Articles/SYAaujep/AaujepVol11 No1Y2013/aaujep_2013-v11-n1_037-057.pdf 
ابن زرقين، محمد (20016). تقنين اختبار المصغوفات المتتابعة المتقدم الجون راشن على الطلبة الجامعيين: دراسة ميدانية على عينة من طلبة جامعة قاصدي مرباح ورقلة. (رسالة ماجستير). سحبت من:

https://dspace.univ-ouargla.dz/jspui/bitstream/123456789/10964/3/ Benrezkin-Mohammed\%20\%281\%29-ilovepdf-compressed.pdf إمراجع، أحمد ؛ عبد الله، صالح (2006). تقنين اختبار المصغوفات المتلدرجة الملون للنكاء

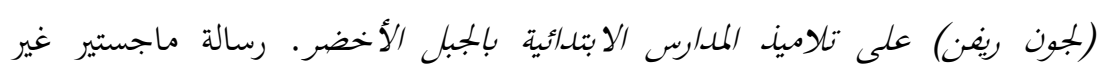
منشورة، أكاديمية الدراسات العليا فرع بنغازي. الديلي، فاطمة عامر(2001). تقنين اختبار رسم الرجل للنكاء على عينات من الاطفال

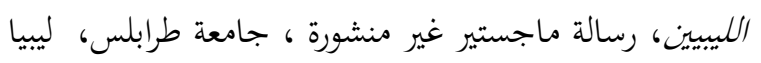
فرج، صفوت (1980). القياس النفسي. القاهرة: دار الفكر العربي.

فرج، صفوت (2011). مقياس ستانفورد بينية للذكاء الصورة الخامسة : دليل المقياس. القاهرة: مكتبة الانجلو.

مخائيل، امطانيوس (2006). القياس النفسي. ج1. منشورات جامعة دمشق.

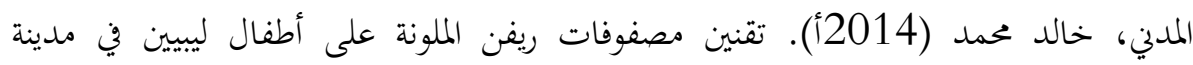

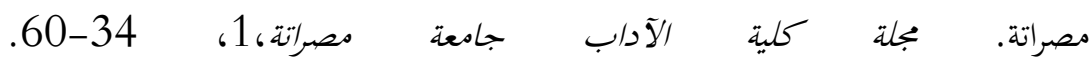
https://doi.org/10.36602/faj.2014.n01.02 المدني، خالد محمد (2014ب). دور اختلاف الثقافة على أداء الأطفال على مصفوفات ريفن

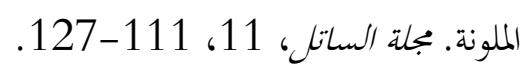

المدني، خالد محمد و الدلنسي، رويدا اسماعيل (2017). الخصائص السيكومترية لاختبار الذكاء

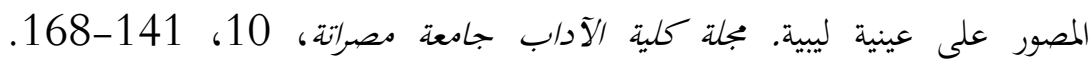
https://doi.org/10.36602/faj.2017.n10.06 النفيعي، عبد الرحمن عبدالله (2001): تقنين اختبار ريفن للمصفوفات المتتابعة المتقدم على

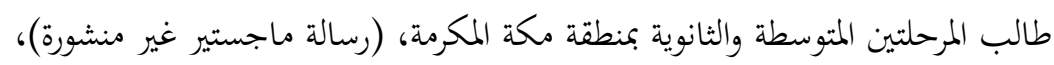

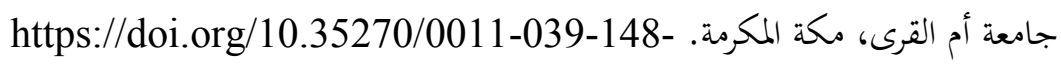
001 


\section{ثانيا : مراجع باللغة الإنجليزية}

Anastasi, A., \& Urbina, S. (1997). Psychological testing (7th ed). New Jersy: Prentice-Hall, Inc

Bors, D., \& Stokes, T. (1998). Raven's Advanced Progressive Matrices: Norms for First-Year University Students and the Development of a Short Form. Educational and Psychological_Measurement. 58(3):382-398. https://doi.org/10.1177/0013164498058003002

Cristobal, E., Flavian, C., \& Guinaliu, M. (2007). Perceived e-service quality (PeSQ) Measurement validation and effects on consumer satisfaction and web site loyalty. Managing service quality: An international journal, 17(3), 317-340. https://doi.org/10.1108/09604520710744326

Elmadani, Khalid (2010). The impact of neuroticism on an individual's intelligence scores: a cross cultural study $(\mathrm{PhD}$ Thesis). retrieved from:

http://irep.ntu.ac.uk/id/eprint/257/1/198033_Elmadani\%20the sis.pdf

Henson, R. K. (2001). Understanding internal consistency reliability estimates: A conceptual primer on coefficient alpha. Measurement \& Evaluation in Counselling \& Development, 34(3), 177. https://doi.org/10.1080/07481756.2002.12069034

Kaufman, A., \& Lichtenberger, E. (2002). Assessing Adolescent and adult intelligence (2nd ed). Boston: Allyn and Bacon.

Raven, J. (2000). The Raven's progressive matrices: Chang anf stability over culture and time. Cognitive Psychology, 4(1), 148. retrieved from: http://www.idealibrary.com 